\title{
Imaging spectroscopy to assess the composition of ice surface materials and their impact on glacier mass balance
}

\author{
Kathrin Naegeli ${ }^{\mathrm{a}, *}$, Alexander Damm $^{\mathrm{b}}$, Matthias Huss ${ }^{\mathrm{a}, \mathrm{c}}$, Michael Schaepman ${ }^{\mathrm{b}}$, Martin Hoelzle ${ }^{\mathrm{a}}$ \\ a Department of Geosciences, University of Fribourg, Chemin de Musée 4, 1700 Fribourg, Fribourg, Switzerland \\ ${ }^{\mathrm{b}}$ Remote Sensing Laboratories, University of Zurich, Winterthurerstrasse 190, 8057 Zürich, Switzerland \\ c Laboratory of Hydraulics, Hydrology and Glaciology (VAW), ETH Zurich, Hönggerbergring 26, 8093 Zürich, Switzerland
}

\begin{abstract}
Glacier surfaces are not only composed of ice or snow but are heterogeneous mixtures of different materials. The occurrence and dynamics of light-absorbing impurities affect ice surface characteristics and strongly influence glacier melt processes. However, our understanding of the spatial distribution of impurities and their impact on ice surface characteristics and the glacier's energy budget is still limited. We use imaging spectroscopy in combination with in-situ experiments to assess the composition of ice surface materials and their respective impact on surface albedo and glacier melt rates. Spectroscopy data were acquired in August 2013 using the Airborne Prism EXperiment (APEX) imaging spectrometer and were used to map the abundances of six predominant surface materials on Glacier de la Plaine Morte, Swiss Alps. A pixel-based classification revealed that about $10 \%$ of the ice surface is covered with snow, water or debris. The remaining $90 \%$ of the surface can be divided into three types of glacier ice, namely 7\% dirty ice, 43\% pure ice and 39\% bright ice. Spatially distributed spectral albedo derived from APEX reflectance data in combination with in-situ multi-angular spectroscopic measurements was used to analyse albedo patterns present on the glacier surface. About $85 \%$ of all pixels exhibit a low albedo between 0.1 and 0.4 (mean albedo $0.29 \pm 0.12$ ), indicating that Glacier de la Plaine Morte is covered with a significant amount of light-absorbing impurities, resulting in a strong ice-albedo feedback during the ablation season. Using a pixel-based albedo map instead of a constant albedo for ice (0.34) as input for a mass balance model revealed that the glacier-wide total ablation remained similar (10\% difference). However, the large local variations in mass balance can only be reproduced using the pixel-based albedo derived from APEX, emphasizing the need to quantify spatial albedo differences as an important input for glacier mass balance models.
\end{abstract}

\section{Introduction}

Glaciers surfaces are neither clean nor homogeneous. In fact, glacier surfaces are heterogeneous mosaics of different materials and structures (e.g. Cuffey \& Paterson, 2010; Oerlemans, 2001). The darkening of glacier surfaces is a phenomenon observed in various regions across the globe, for example in the European Alps (e.g. Oerlemans, Giesen, \& Van Den Broeke, 2009), the Himalayas (Takeuchi, 2001), or on the Greenland ice sheet (Dumont et al., 2014). The existence of materials that are darker compared to actual bare-ice surfaces has a large impact on ablation, eventually enhancing glacier melt. This feedback becomes particularly important in the context of climate change and strong glacier retreat, since it hampers our capability to project the future of glacier ice worldwide (e.g. Flanner, Zender, Randerson, \& Rasch, 2007; Painter, Bryant, \& McKenzie Skiles, 2012; Xu et al., 2009).

Recent studies have shown that light-absorbing impurities, e.g. mineral dust, soot, black carbon, or other organic matter, are crucial

\footnotetext{
* Corresponding author.

E-mail address: kathrin.naegeli@unifr.ch (K. Naegeli).
}

in defining melt rates of snow and ice and influence processes across a large range of temporal and spatial scales (Alexander et al., 2014; Oerlemans et al., 2009; Pedersen, Berntsen, Gerland, \& Warren, 2010). In most cases, a decrease in surface reflectance due to impurities increases the light absorbance causing enhanced snow and ice melt and therefore represents a positive feedback.

Several research activities have been carried out to investigate the feedback between ice and snow melt and light absorbance. Organisms living on snow and ice surfaces, for example, have received considerable attention while focusing on their distribution, biological activities, as well as their morphodynamics (Hodson et al., 2010; Wharton, McKay, Simmons, \& Parker, 1985). Further, in-situ sampling and remote sensing was used to study cryoconite (Langford, Hodson, Banwart, \& Bøggild, 2010; Takeuchi, 2002a), glacier facies (Klein \& Isacks, 1999; Nolin \& Payne, 2007; Pope \& Rees, 2014), and debris composition on glacier surfaces (Casey, 2011). Yet other studies apply time-lapse imaging and automatic weather stations to monitor cryoconite or albedo locally (Irvine-Fynn, Bridge, \& Hodson, 2011; Oerlemans \& Knap, 1998). Especially in snow science, remote sensing techniques revealed important and essential information about snow 
coverage, snow properties such as grain size or liquid water content, and snow albedo (Dozier, Green, Nolin, \& Painter, 2009; Joerg, Weyermann, Morsdorf, Zemp, \& Schaepman, 2015; Nolin \& Dozier, 2000; Painter, Seidel, Bryant, McKenzie Skiles, \& Rittger, 2013; Painter et al., 2009).

Despite the various research lines and efforts related to snow, little is yet known about similar aspects considering bare ice that appears in the ablation area of glaciers after the melting of winter snow. This limits current process understanding since impurities and surface albedo are two factors crucially determining ice ablation. Bare-ice surfaces represent a large, and - in times of warmer and longer summers - growing fraction of all ice masses worldwide, thus increasingly provoking the ice-albedo feedback.

Compared to snow, bare-ice surfaces tend to be more heterogeneous across spatial scales, complicating the characterization of surface properties and quantitative assessments of light-absorbing impurities. Furthermore, liquid water present on glacier surfaces is able to efficiently reallocate and transport impurities, adding a temporal component to the complexity of respective assessments (Chandler, Alcock, Wadham, Mackie, \& Telling, 2014). Concerning the ability to determine ice surface albedo, various factors such as surface roughness, presence of water, crystal size, anisotropic effects, and many others have a large influence (e.g. Cuffey \& Paterson, 2010) and thus challenge the retrieval of ice surface albedo. Existing satellite-based approaches to distinguish glacierwide albedo values (Dumont et al., 2012; Knap, Reijmer, \& Oerlemans, 1999; Paul, Machguth, \& Kääb, 2005) typically suffer from a scaling mismatch since sampling distances (pixel sizes) are much coarser than albedo variability of the ice surface (e.g. Azzoni et al., 2014).

The global importance of rapid and ongoing glacier melt requires dedicated research focusing on the dynamics and underlying processes of bare-ice surface albedo changes. In particular the divergence between typical spatio-temporal length scales of melting processes and state-ofthe-art remote sensing or in-situ field sampling demands more suitable and interdisciplinary methodologies. In this paper we demonstrate the applicability of a combined approach using observations and models to improve current knowledge about the temporal and spatial distribution of light-absorbing impurities on bare-ice surfaces and to assess their impact on glacier albedo and the energy and mass balance of glaciers. In particular, we use in-situ and airborne spectroscopy data and a highresolution orthoimage (i) to map the distribution of different glacier surface materials and (ii) retrieve a glacier-wide spectral albedo map. Furthermore, we apply a mass balance model to (iii) evaluate the impact of glacier surface albedo on calculated mass balance distribution.

\section{Study site and data}

\subsection{Study site}

Glacier de la Plaine Morte $\left(46^{\circ} 23^{\prime} \mathrm{N}, 7^{\circ} 30^{\prime} \mathrm{E}\right)$ is the largest plateau glacier in the European Alps covering an area of $7.52 \mathrm{~km}^{2}$ in 2013. The glacier is located on the main water divide between the Rhine and the Rhone River in the Bernese Alps, western Switzerland (Fig. 1). The

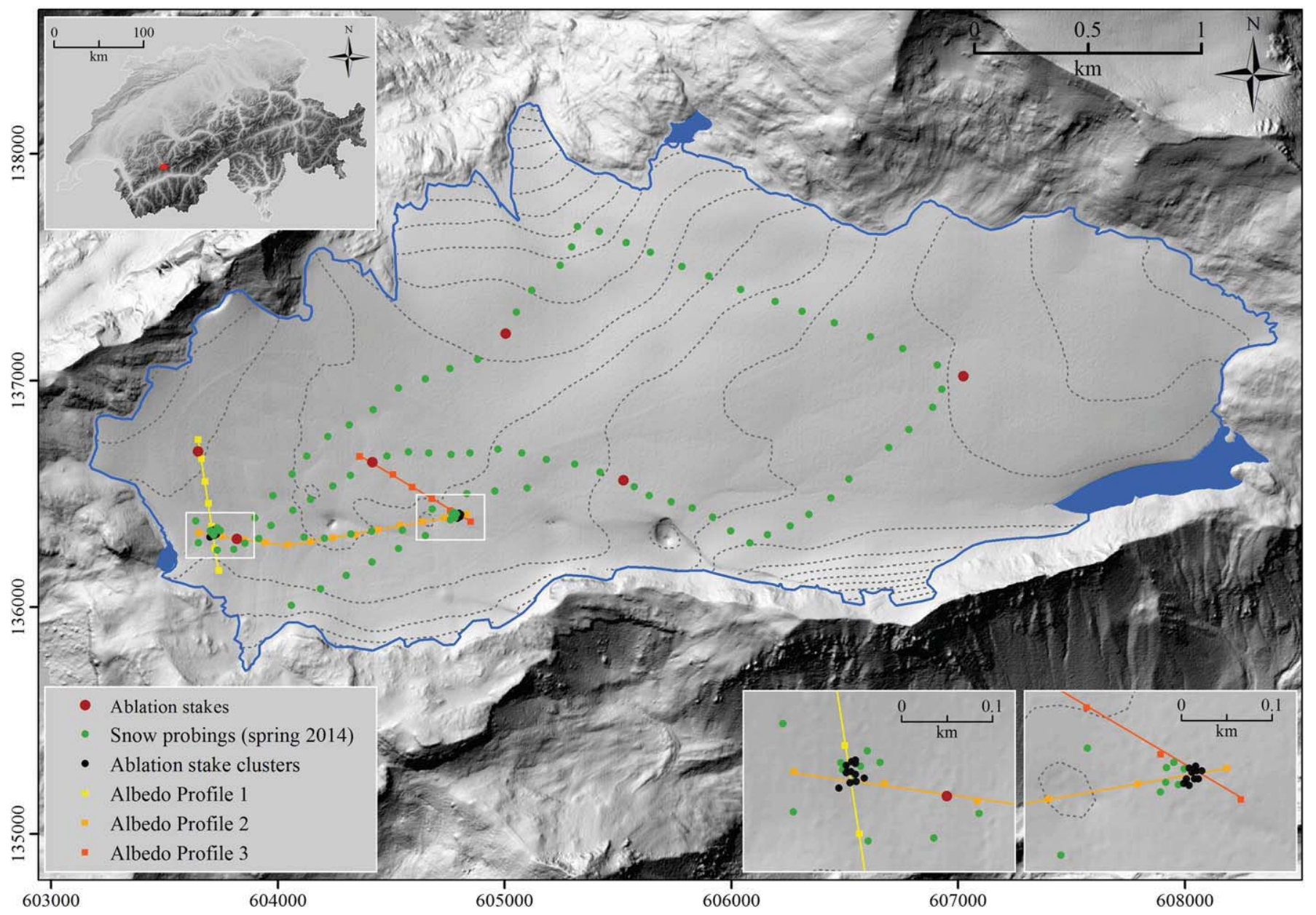

Fig. 1. Glacier de la Plaine Morte and its location within Switzerland (upper left inset). The location of various in-situ measurements of the past years are marked with different symbols and colours. The insets show the ablation stake clusters (for more explanations see Section 2.6). The blue line delineates the glacier outline in 2013 and the blue polygons represent three supraglacial lakes in 2010. Coordinates refer to the Swiss national grid (CH1903). 
glacier is characterized by a very narrow altitudinal range, with $90 \%$ of the glacier surface between 2650 and $2800 \mathrm{~m}$ above sea level (a.s.l.). This results in an average slope of less than $4^{\circ}$ over the $\sim 5 \mathrm{~km}$ wide plateau. During the last years, the entire glacier was snow-free by mid-August, i.e. the equilibrium line was above the glacier, indicating a strongly negative mass balance and causing a significant ice-albedo feedback. Based on a ground-penetrating radar survey, a mean ice thickness of $104 \mathrm{~m}$, a maximum ice thickness of $226 \pm 18 \mathrm{~m}$, and a glacier volume of $0.82 \pm 0.1 \mathrm{~km}^{3}$ was obtained for the year 2011 (Huss, Voinesco, \& Hoelzle, 2013). Towards the north, a small glacier tongue, the Rezligletscher, forms the only active outlet flow feature compared to the rest of the glacier where ice flow is very limited. Hence, surface crevasses are rare. However, large circular cryocarst depressions and long supraglacial meltwater streams leading to temporally stable moulins are typical for Glacier de la Plaine Morte. Dye tracing experiments showed that most meltwater drains along the glacier bed to the north and reappears at the tongue of Rezligletscher. However, a significant fraction of the surface melt from the western part of the glacier enters the karstic system connected to the Rhone Valley through subsurface conduits crossing the main surface water divide (Finger et al., 2013). Furthermore, three glacier marginal lakes around Glacier de la Plaine Morte are observed since several years (Fig. 1). All lakes form on impermeable sediments and are dammed by the ice on one side, making them potentially instable. All lakes gain in volume from year to year, resulting in noticeable subglacial drainage events (Huss et al., 2013).

Field surveys revealed that besides different types of glacier ice, snow, water and debris are the predominant materials present on the surface of Glacier de la Plaine Morte during the ablation season. Since 2002, the equilibrium line altitude was constantly above the highest point of the glacier. This results in limited snow-covered areas and thus only very small accumulation areas if at all. Water is mainly present in supraglacial streams, ponds and lakes but also all over the glacier surface as water film on blue ice, in cryoconite holes, and as intrinsic part of wet snow or wet debris. However, liquid water contained in these mixtures is not relevant for this study. Debris is characterized by aggregations of mineralogical and organic material; the exact composition of these debris piles is however unknown. Besides these three nonice materials, we distinguish between three different types of ice, being aware of the smooth transition between them and other possible stratifications. The brightest ice type is named bright ice and characterized by its rather brittle surface, large crystals and voids filled with air ( similar to "white ice" in Pope \& Rees, 2014). In contrast, dirty ice represents an ice surface that is covered by fine particles leading to a considerable darkening of the surface (similar to "debris ice" and "very debris ice" in Pope \& Rees, 2014). In between these two extreme ice types, we identified a type termed ice that consists of blue-greyish, solid ice with very little or no impurities and only a thin water film if at all. A photograph typical for each surface type is presented in Appendix A (Fig. A1).

\subsection{Airborne spectroscopy}

Spectral data of the glacier was acquired during two overflights with the Airborne Prism EXperiment (APEX) imaging spectrometer on August 31st 2013 between 10:15 a.m. and 10:24 a.m. Central European Summer Time (CEST) under cloud-free conditions. The flying altitude of $4000 \mathrm{~m}$ above ground level (a.g.l.) in combination with an instantaneous field of view (FOV) of $0.0025^{\circ}$ resulted in a surface projected pixel resolution of $\sim 2 \mathrm{~m}$. APEX is a dispersive pushbroom imaging spectrometer, covering the spectral wavelength range between 400-2500 nm in 313 narrow continuous spectral bands (Schaepman et al., 2015). Radiometric and spectral calibration of measured raw signals was done using the APEX Processing and Archiving Facility (PAF), allowing us to convert raw data streams into calibrated level 1 at-sensor radiances (Hueni, Lenhard, Baumgartner, \& Schaepman, 2013; Jehle et al., 2010). Calibrated radiances were subsequently orthorectified using the Parametric Geocorrection (PARGE) software (Schläpfer \& Richter, 2002) and a combined atmospheric/topographic correction was applied using the ATCOR-4 software to obtain Hemispherical-Conical-Reflectance Factor (HCRF) data (Richter \& Schläpfer, 2002). ATCOR-4 approximates atmospheric absorption and scattering effects using the atmospheric radiative transfer model MODTRAN-5 (Berk et al., 2005). Required model input parameters describing the atmospheric status during overflight were set to values derived from prior information. Aerosol optical thickness or atmospheric water vapour was retrieved from the image data itself. Aerosol particle size and distribution were approximated using MODTRAN-5 predefined parametrization schemes (e.g. mid latitude summer with a rural atmosphere). Reflectance anisotropy causes angular variations of surface HCRF and leads to radiometric differences depending on view angle as well as in the overlapping region of both flight lines. Both flight lines were therefore corrected to minimize anisotropy effects using the Rogge, Bachmann, Rivard, and Feng (2012) approach. Finally, the fight lines were mosaicked for subsequent analysis.

\subsection{FieldSpec spectroscopy}

Nadir and directional in-situ radiometric measurements of pure surface materials were obtained using an ASD FieldSpec Pro (Analysis Spectral Device, Boulder, USA) field spectrometer to compile a sitespecific spectral library for validation purposes, to facilitate a surface classification (cf. Section 3.1), and to retrieve maps of spectral surface albedo from the airborne data (cf. Section 3.2). The field spectrometer measures in the spectral range between $350-2500 \mathrm{~nm}$, has a spectral sampling interval of $1.4 \mathrm{~nm}(350-1000 \mathrm{~nm})$ and $2 \mathrm{~nm}(1000-$ $2500 \mathrm{~nm}$ ), and a full width half maximum of $3 \mathrm{~nm}$ at $700 \mathrm{~nm}$ and $10 \mathrm{~nm}$ at $1400 \mathrm{~nm}$ (Analytical Spectral Devices, I., 2014). Nadir radiometric measurements were taken \pm two hours around the airborne overpasses (i.e., 09:00 a.m. to 01:00 p.m. CEST) under clear-sky conditions, while directional measurements were acquired in August 2014 under comparable conditions.

One or a few locations were selected for what was determined to be the area's representative surface type. Nadir radiance measurements were collected with a bare fibre optic $\sim 1 \mathrm{~m}$ above the surface yielding in a circular sampled surface area of $\sim 40 \mathrm{~cm}$ in diameter. Incident light was quantified before and after target measurements using a Spectralon reference panel, allowing us to obtain surface HCRF data. Additionally, directional measurements of respective materials were taken one year later. At each reference site we measured angles ranging from $0^{\circ}, 30^{\circ}$, $60^{\circ},-30^{\circ}$ and $-60^{\circ}$, both in the solar principal plane and perpendicular to it, enabling us to quantify surface specific reflectance anisotropy of the different materials. Likewise to the measurements described above, a Spectralon reference panel was used to quantify irradiance and to eventually calculate HCRF values.

\subsection{High resolution orthoimage and digital surface model}

A high-resolution orthoimage $(0.25 \times 0.25 \mathrm{~m}$ pixel size $)$ provided by Swisstopo was available for this study. The image was taken on the 21st of August 2013, ten days before the APEX overflight. During this earlier acquisition date, a slightly larger snow cover was present on the glacier surface. Despite the minor difference in snow coverage between both acquisition dates, the orthoimage represents a rather unchanged glacier surface as compared to the APEX over flight and is therefore an optimal dataset to validate the results obtained from APEX data. From the orthoimage, we also delineated a contemporary glacier outline, which was used as glacier mask for all analyses.

We used a digital elevation model at $25 \mathrm{~m}$ spatial resolution (DHM25) (Swisstopo, 2005) to calculate the spectral albedo map and as input to the mass balance model. 


\subsection{In-situ surface albedo measurements}

During the ablation season 2014, in-situ albedo measurements were acquired using a Kipp \& Zonen CM7B albedometer $(\lambda=305-2800 \mathrm{~nm})$ mounted on a tripod to ensure readings parallel to the surface plane. Along three profiles, 27 individual points were measured three to six times between 3rd of July and 14th of September 2014. The height of the albedometer above the glacier surface was set to $1 \mathrm{~m}$ and the sensor was pointing south-wards. The footprint of the albedometer is theoretically infinite since it has a hemispherical FOV of $180^{\circ}$. However, $50 \%$ of the signal originates within a FOV of $90^{\circ}$ (Cescatti et al., 2012). Therefore, considering the setup used for this study, the effective footprint is about $3.1 \mathrm{~m}^{2}$, which corresponds to the pixel size of APEX. All measurements were acquired within three hours of local solar noon and the present cloud cover was noted. Furthermore, albedometer measurements were complemented with meta data such as actual surface types and photographs to facilitate the interpretation of measured surface albedo values.

\subsection{Glacier mass balance measurements}

Seasonal mass balance measurements are carried out on Glacier de la Plaine Morte since 2009 based on the direct glaciological method. Summer balance is monitored using a network of at least four ablation stakes (Fig. 1) surveyed two to four times over the ablation season. The observed small overall variation of ablation justifies the limited number of measurement sites to capture spatial ablation patterns. Winter balance is based on 100-200 probings (depending on the survey year) distributed over the entire glacier surface (Fig. 1). To determine the snow density, one or two snow pits are dug during the measurement campaign in spring (Huss et al., 2013).

The influence of "bright" and "dark" surface ice types on glacier melt is evaluated using two ablation stake clusters with twelve and ten stakes, respectively. The 22 stakes were each $2 \mathrm{~m}$ long and placed in the ice using a steam drill on August 16th 2013 just after the disappearance of the last winter snow (Fig. 1). The ablation stake clusters were surveyed several times throughout the ablation season until October 2nd 2013.

\section{Methods}

\subsection{Glacier surface classification and estimation of pixel abundances}

We applied the spectral angle mapper (SAM) classification algorithm (Kruse et al., 1993) to determine the distribution and pixel abundance of six predominant surface materials present on the glacier surface, i.e., debris, dirty ice, water, ice, bright ice and snow (cf. Section 2.1). These materials largely differ in their spectral albedo and hence critically impact any model-based calculations of glacier mass balance. The SAM compares reference spectral signatures, also termed endmembers, with image spectra by treating them as vectors in an n-dimensional data space. The agreement of endmember and image spectra is quantified as spectral angle $\alpha$ with

$\alpha=\cos ^{-1}\left(\frac{\sum_{i=1}^{n b} t_{i} r_{i}}{\left(\sum_{i=1}^{n b} t_{i}^{2}\right)^{\frac{1}{2}}\left(\sum_{i=1}^{n b} r_{i}^{2}\right)^{\frac{1}{2}}}\right)$,

where $n b$ is the number of bands, $t$ is the target spectrum and $r$ the endmember spectrum (Kruse et al., 1993). The classification itself is based on a user-defined threshold of $\alpha$, while $\alpha$ itself can be interpreted as a value quantifying the similarity between endmember and target spectra (Bell, Breitler Bowen, \& Martini, 2010). The smaller the angle $\alpha$, the more similar are the two compared spectra (Exelis Visual Information Solutions, 2013). An important advantage of the SAM is that it does not take the length of the vector into account, which corresponds to the signal intensity. This makes the SAM rather insensitive to remaining topographical effects in HCRF data after the atmospheric compensation (Aspinall, Marcus, \& Boardman, 2002).

The spectral library used for the SAM analysis is built using endmember spectra extracted from APEX data. We used the highresolution orthoimage to identify ten pure pixels per surface type based on expert knowledge and field visits. Co-registration between orthoimages and APEX data was better than one APEX pixel in $\mathrm{x}$ and $\mathrm{y}$ directions ( $\pm 2 \mathrm{~m}$ ), allowing us to uniquely identify pure pixels with high fidelity. Following pure pixel selection, all ten spectra representing one endmember were averaged into one representative endmember spectrum (cf. Fig. 2 and Appendix A, Fig. A2). The SAM algorithm was only applied to the glacierized area of the image scene using the glacier mask of 2013.

\subsection{Estimation of spatially distributed spectral albedo}

Spectral albedo was approximated from HCRF data considering the wavelength range from 400 to $2500 \mathrm{~nm}$. Since reflectance anisotropy causes differences between HCRF and BHR (Bi-Hemispherical Reflectance) that is usually named albedo (Schaepman-Strub, Schaepman, Painter, Dangel, \& Martonchik, 2006), we used in-situ directional measurements to obtain coefficients for correcting differences between HCRF and BHR data. The correction coefficients were calculated for each viewing angle considering almost the entire hemisphere and were represented in a surface-specific polar plot (cf. Fig. 2 and Appendix A, Fig. A3). Directional in-situ measurements of surface HCRF were obtained in and perpendicular to the solar principle plane considering a view zenith angle range of $\pm 60^{\circ}$ (cf. Section 2.3, Appendix A, Fig. A4). Missing HCRF values of the polar plot were linearly interpolated $\left(\mathrm{HCRF}_{\mathrm{pp}}\right)$. A reference $\mathrm{BHR}$ of a certain surface was approximated by integrating the HCRF $\mathrm{pp}_{\mathrm{p}}$ values of the entire hemisphere as

$\mathrm{BHR}=\int_{0}^{2 \pi} \int_{0}^{\pi / 2} \operatorname{HCRF}_{\mathrm{pp}}\left(\theta_{v_{i}}, \varphi_{v_{i}} ; 2 \pi\right)$,

where $\theta_{v}$ is the view zenith angle and $\varphi_{v}$ is the view azimuth angle. To calculate a correction factor specific to a certain view angle, we multiplied the corresponding $\mathrm{HCRF}_{\mathrm{pp}}$ value with $\pi$ to obtain a view angle specific apparent $\mathrm{BHR}(\mathrm{BHRa})$ and determined the correction factor $(c)$ as ratio between the true BHR and the angular specific BHRa as

$c\left(\theta_{v}, \varphi_{v}\right)=\frac{\operatorname{BHRa}\left(\theta_{v}, \varphi_{v}\right)}{\operatorname{BHR}}$

while

$\operatorname{BHRa}\left(\theta_{v}, \varphi_{v}\right)=\operatorname{HCRF}\left(\theta_{v}, \varphi_{v}\right) \cdot \pi$

To extract the exact pixel-wise correction factor from the polar plot, we used the flight heading information to define the view azimuth angle and calculated an effective view zenith angle $\left(V Z A_{\text {eff }}\right)$ considering the sensor view angle and the surface orientation as

$\cos \left(V Z A_{\text {eff }}\right)=\cos \theta_{v} \cos \theta_{n}+\sin \theta_{s} \sin \theta_{n} \cos \left(\varphi_{s}-\varphi_{n}\right)$,

while $\theta_{n}$ is the normal zenith angle (slope) and $\varphi_{n}$ is the normal azimuth angle (aspect), both obtained form a digital elevation model.

\subsection{Mass balance model}

We used a spatially distributed glacier mass balance model ( $25 \times$ $25 \mathrm{~m}$ resolution) calibrated to the in-situ measurements to extrapolate the ablation and accumulation point measurements over the glacier surface. The model allows the determination of seasonal glacier volume changes in water equivalent (w.e.). A detailed description of the used 


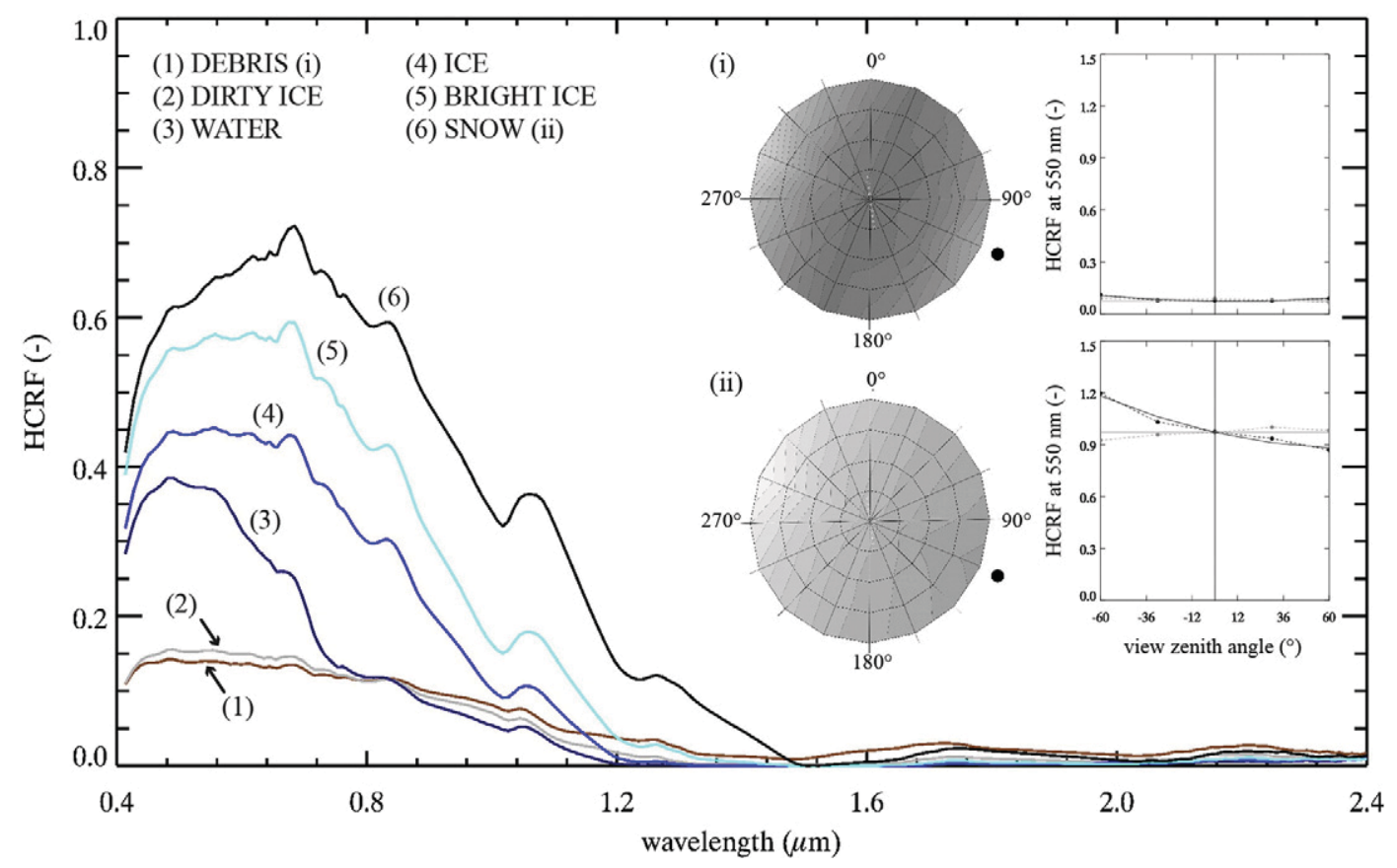

Fig. 2. Overview of six average endmember spectra extracted from the APEX scene (1)-(6). Polar plot of view angle specific correction coefficients, the dark dot indicates the position of the sun; and directional in-situ HCRF measurements taken in the solar principal plane and perpendicular to it, for debris (i) and snow (ii).

model is given in Huss, Bauder, and Funk (2009) and Huss, Zemp, Joerg, and Salzmann (2014). The model components relevant to our study are briefly summarized hereafter.

Daily mean air temperature, global radiation and precipitation sums used to force the model are recorded at an automatic weather station at Montana ( $8 \mathrm{~km}$ from the study site, $1508 \mathrm{~m}$ a.s.l.). The elevation difference between the station in Montana and the glacier is considered using monthly lapse rates derived from surrounding stations. Similarly, a correction factor allows the adjustment of precipitation sums to accumulation as observed on the glacier. A temperature threshold is implemented to distinguish between solid and liquid precipitation.

The energy available for snow or ice melt $Q_{M}$ is calculated based on a simplified energy balance formulation proposed by Oerlemans (2001) as

$Q_{M}=(1-\alpha(x, y, t)) \cdot G(x, y, t)+k_{0}+k_{1} T$,

where $\alpha(x, y, t)$ is the local surface albedo at day $t$ and grid cell $(x, y)$ and $G(x, y, t)$ is the global incoming shortwave radiation in $\mathrm{W} \mathrm{m}^{-2} \cdot k_{0}$ and $k_{1}$ are constant parameters that, in sum with the air temperature $T$, define the longwave radiation balance and the turbulent heat exchange linearized around the melting point (Machguth, Paul, Hoelzle, \& Haeberli, 2006; Oerlemans, 2001).

Surface albedo is either considered to be constant or can be defined for each cell individually based on a spatial map. The temporal evolution of the snow albedo is modelled using a snow ageing function according to Oerlemans \& Knap, 1998.

\section{Results}

\subsection{Abundance of glacier surface materials}

Spectral angles derived from SAM indicate the similarity between pixel and endmember spectra and were used to quantify the abundance of the six different surface materials per individual pixel (Fig. 3). We defined thresholds to distinguish between high $(\alpha<0.025)$, medium $(0.025<\alpha<0.05)$, and low $(0.05<\alpha<0.1)$ abundances. For pixels with values above the highest threshold $(\alpha>0.1)$ the materials were categorized as not present. Only for the two endmembers debris and water the thresholds had to be slightly adjusted, to $0.05,0.1$ and 0.15 .
While debris, water and snow are spatially concentrated, the three ice types exhibit a dispersed abundance pattern.

Whereas the endmember debris is only present in two distinct areas in the western part of the glacier and along the border close to the surrounding periglacial rock and debris, dirty ice shows a low abundance in almost the entire western half of the glacier. However, two distinct areas with medium to high abundances of dirty ice can be distinguished at the same location as debris. A highly concentrated abundance pattern is visible for the endmember water. Except for some single pixels, it is only present in the area of a supraglacial lake (cf. inset in Fig. 3c). Snow shows a high occurrence on the north-facing slopes as well as in some smaller areas along the border of the glacier (avalanche deposits). A low abundance of snow can also be found in the centre of the eastern part and in very small concentrated areas in the western half of the glacier. The endmember ice exhibits medium to high abundances over almost the entire glacier surface. Exceptions are areas where snow or dirty ice have medium to high abundances. Similar to ice, bright ice shows a dispersed pattern of low to high abundances. However, the two endmembers ice and bright ice occur almost everywhere on the glacier and display a contrasting pattern, i.e. high abundances of ice correspond with low abundances of bright ice (Fig. 3).

Table 1 shows the distribution of the three abundance classes (low, medium, high) per endmember. Considering the total off all abundance classes, ice and bright ice are most frequent (78.6\% and $82.3 \%$ ), whereas dirty ice occurs on less than half of the glacier surface (41.1\%). In contrast, the three spatially concentrated endmembers debris, water and snow have small overall total abundances with $2.3 \%, 0.02 \%$ and $12.9 \%$, respectively. While ice, bright ice and snow exhibit equally distributed values between the three classes, the endmember dirty ice and debris are almost only represented with low abundances. The maximum value in the abundance class high is found for the endmember ice (12.6\%) followed by bright ice (9.1\%) and snow (3.2\%). These are the endmember that are mapped most explicitly, compared to debris, dirty ice and water.

\subsection{Surface classification}

Six glacier surface materials were classified to determine the most dominant materials on a pixel basis (Fig. 4), although a mixture of these materials is likely to occur within one pixel (cf. Fig. 3). For the 

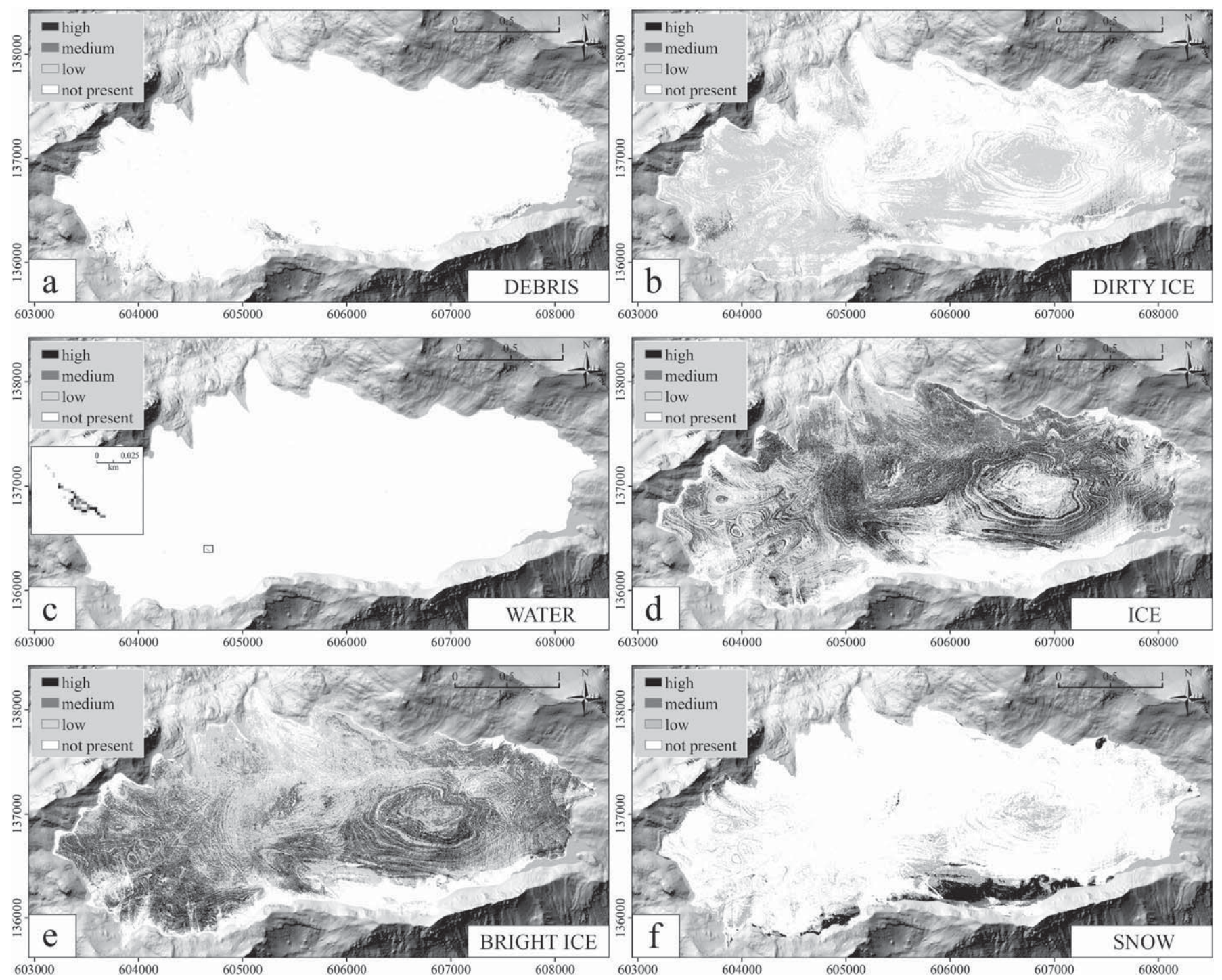

Fig. 3. Abundance maps of six different materials: (a) debris, (b) dirty ice, (c) water, (d) ice, (e) bright ice and (f) snow. The inset in (c) shows a zoom-in of a supraglacial lake.

classification no fixed spectral angle threshold was used. Instead an endmember was assigned to a pixel if its SAM angle was smallest, i.e. the pixels spectrum was most similar to the spectrum of this specific material compared to other endmembers. Water and debris were the least abundant materials with $0.4 \%$ and $2.0 \%$ coverage of the total glacier surface, respectively. The two endmembers dirty ice and snow (6.8\% and $8.3 \%$ coverage) occur more often but are still much less frequent than bright ice and ice with a coverage of $38.9 \%$ and $43.6 \%$ (Table 1 ).

Similar to the abundance pattern shown in Fig. 3, pixels were classified as snow along the border of the glacier, most prominently on the south-side. Furthermore, an avalanche cone is visible at the northeastern glacier margin. Likewise, debris pixels were mostly classified below rocky slopes surrounding the glacier. However, debris can also

Table 1

Distribution of abundance classes per endmember in percent. The bottom line "classified" shows the proportion of each endmember in the classification image (Fig. 4).

\begin{tabular}{lcccccc}
\hline Abundance & Debris & Dirty ice & Water & Ice & Bright ice & Snow \\
\hline High & 0.0 & 0.0 & 0.00 & 12.6 & 9.1 & 3.2 \\
Medium & 0.4 & 1.4 & 0.00 & 29.6 & 30.6 & 2.1 \\
Low & 1.9 & 39.7 & 0.02 & 36.5 & 42.6 & 7.7 \\
Not present & 97.7 & 58.9 & 99.98 & 21.4 & 17.7 & 87.1 \\
\hline Classified & 2.0 & 6.8 & 0.4 & 43.6 & 38.9 & 8.3 \\
\hline
\end{tabular}

be found along supraglacial meltwater streams, most prominently in the confluence zone of several channels in the western part east of the dirty ice area (cf. Fig. 5). Dirty ice is classified in two large areas in the western half of the glacier but also in smaller patches elsewhere. The classified water pixels are in good agreement with the abundance pattern shown in Fig. 3 as well, as only a very limited amount of pixels was attributed to the endmember water (cf. Fig. 5). Moreover, the areas along the south side of the glacier are most likely wrongly classified as these are in the shadow and should therefore not be attributed to the endmember water. The two most dominantly represented endmembers are obviously ice and bright ice. Whereas ice is predominant in the northern area of the Rezligletscher tongue, bright ice was most frequently classified in the western parts and in the dome-shaped area to the east.

The classification adequately displays the pattern of the six predominant surface materials. Even small-scale features such as moulins, supraglacial streams and lakes are revealed. To illustrate this, two examples are shown in Fig. 5: An about $40 \mathrm{~m}$ long supraglacial lake was present during image acquisition (Fig. 5a) and is also clearly visible in the high-resolution orthoimage (Fig. 5b). The SAM classification successfully detected the lake (Fig. $5 \mathrm{c}$ ), although we found confusion with the underlying ice classes. This mis-classifications demonstrates the difficulty of detecting shallow water over bright surfaces or mixed pixels at the border of the water body if using spectral properties only since a minimum water depth is required (e.g. Fitzpatrick et al., 2014; 


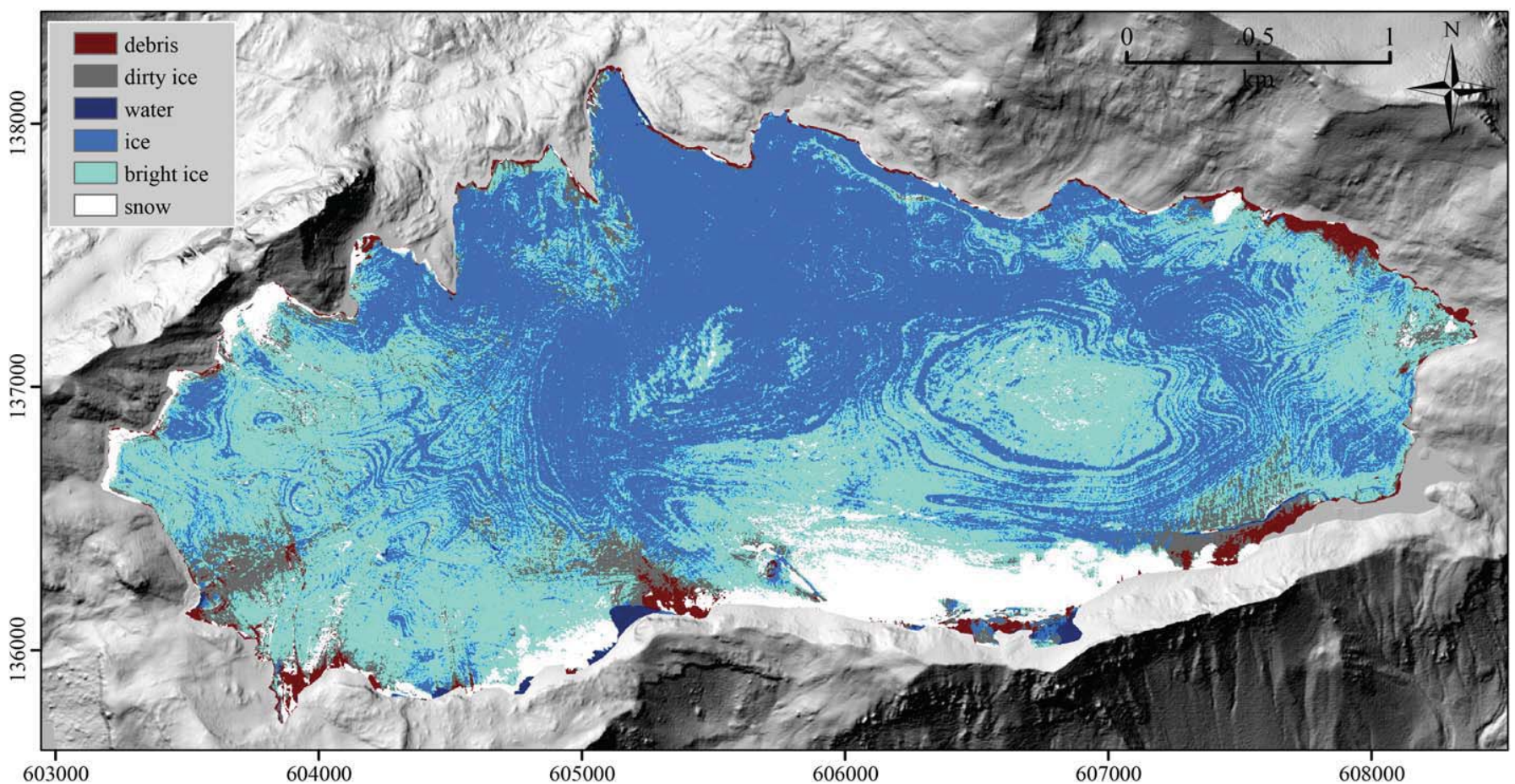

Fig. 4. Glacier surface classification of the six predominant materials: debris, dirty ice, water, ice, bright ice and snow.

Legleiter, Tedesco, Smith, Behar, \& Overstreet, 2014). The second example, the confluence zone of several supraglacial channels, is a small-scale feature that consists of a flat area with debris piles, meltwater streams and different types of ice in between them (Fig. 5d, e). This rather dark, very heterogeneous area is clearly visible in the high-resolution orthoimage (Fig. 5f). Fig. 5g shows the corresponding area in the SAM classification. The amount of debris classified is rather large and can be questioned; however details such as a small snowbank are well represented, highlighting the level of accuracy of the classification as well as the ability to reproduce the heterogeneity of different materials present on the glacier surface.

A confusion matrix (Foody, 2002) was calculated (Table 2) to quantitatively validate the APEX-based SAM classification. Based on the high-resolution orthoimage 100 points were manually classified.
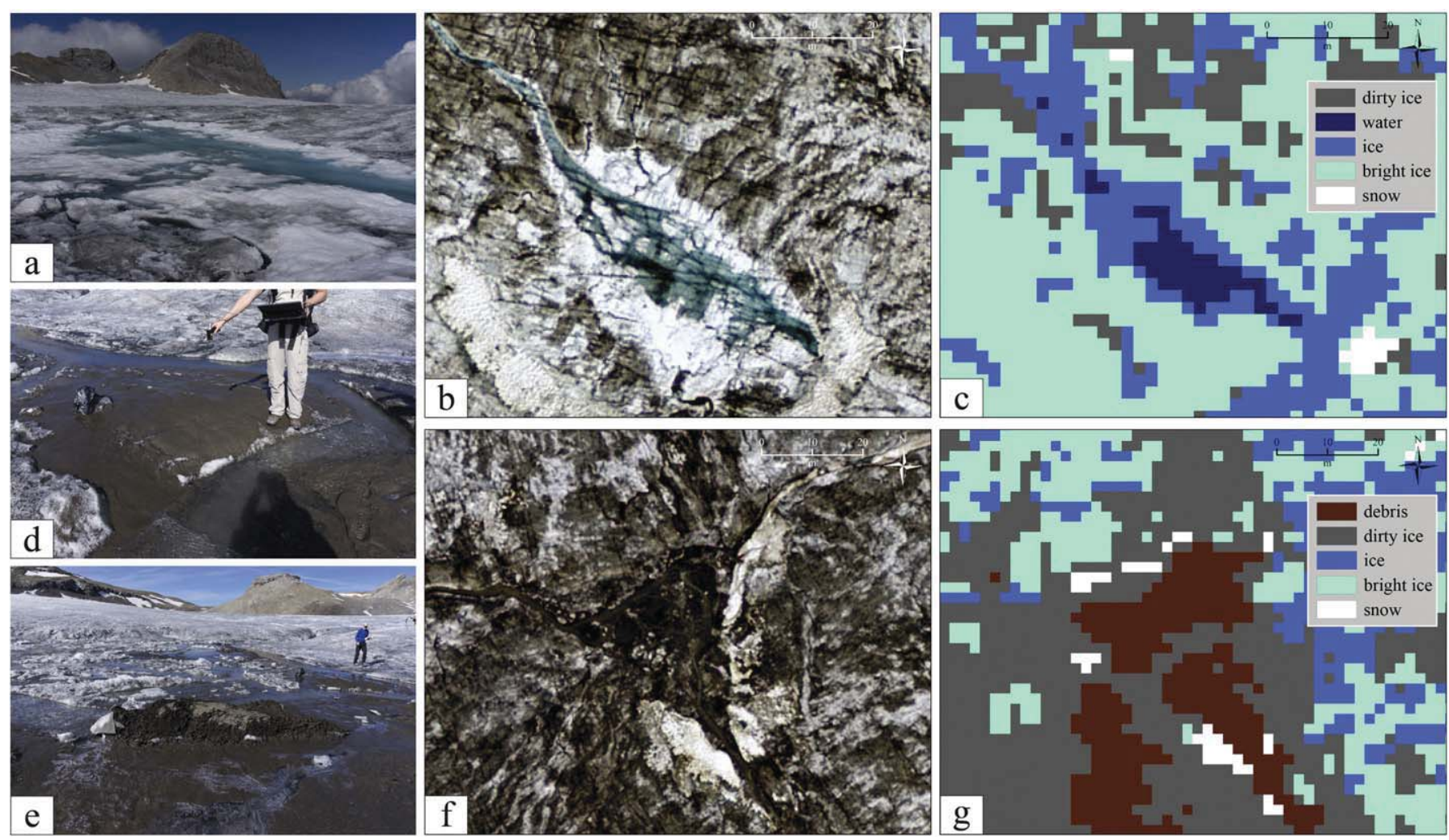

Fig. 5. Supraglacial lake and stream confluence with debris piles shown as pictures (a),(d),(e); as imaged by the high-resolution orthoimager (b),(f); and in the classified APEX image (c),(g). 
Table 2

Confusion matrix of the SAM results and ground truth data listed as percentage classification accuracy.

\begin{tabular}{lcccrrr}
\hline Ground truth & Classified & & & & & \\
\cline { 2 - 6 } [Sample size] & Bright ice & Debris & Dirty ice & Ice & Snow & Water \\
\hline Bright ice [18] & 56 & 0 & 0 & 39 & 6 & 0 \\
Debris [15] & 0 & 87 & 0 & 7 & 7 & 0 \\
Dirty ice [20] & 5 & 15 & 65 & 15 & 0 & 0 \\
Ice [23] & 30 & 0 & 0 & 65 & 4 & 0 \\
Snow [17] & 0 & 0 & 0 & 0 & 100 & 0 \\
Water [7] & 14 & 0 & 0 & 29 & 0 & 57 \\
\hline
\end{tabular}

We selected 15-23 reference points for the endmembers debris, snow, bright ice, dirty ice and ice and only seven for endmember water because of its small abundance across the glacier. The validation revealed an overall classification accuracy of $72 \%$ and a kappa coefficient (Cohen, 1960 ) of 0.86 . The two endmembers debris and snow were classified with very high accuracies of $87 \%$ and $100 \%$ respectively. A medium to high accuracy of $65 \%$ was found for the endmembers dirty ice and ice. The lowest accuracies were calculated for bright ice and water with $56 \%$ and $57 \%$ respectively. Largest confusion was found for bright ice and ice, which can be explained by the difficulty to distinguish between them even during manual classification and their gradual transition in nature. Furthermore, the shallow water showed relatively large confusion with ice and bright ice since the APEX sensor basically looks through the water and is likely to detect the material underneath (Fig. 5a, c). The degree of agreement can be stated excellent, according to the notation by Monserud and Leemans (1992).

\subsection{Glacier surface albedo}

A spectral albedo map ( $\lambda=400-2500 \mathrm{~nm})$ of the glacier surface was computed based on APEX HCRF data (cf. Section 3.2), revealing a mean albedo value of $0.29 \pm 0.12$ for Glacier de la Plaine Morte (Fig. 6). This average value agrees well with the recommended albedo values for clean ice $(0.35)$ and debris-rich ice $(0.20)$ according to Cuffey and
Paterson (2010). For few small and concentrated snow-covered areas high albedo values were computed. Furthermore, in shadowed areas along the southern border of the glacier, unrealistic albedo values close to zero were derived.

The partitioning of all albedo values into 10 classes (Fig. 7) indicated that the majority of all pixels (85\%) had an albedo between 0.1 and 0.4 . Another $8 \%$ of the glacier surface showed an albedo between 0.4 and 0.5 . Albedo values smaller than 0.1 or greater than 0.5 were attributed to only about $6 \%$ of the pixels.

We used 27 individual in-situ point albedo measurements taken on 6th and 28th of August 2014 to assess the accuracy of the computed absolute albedo values. We are aware of the one-year time discrepancy between these two data sets, however no APEX overflight was possible due to adverse weather in summer 2014. As shown in Fig. 8, the albedo values derived from APEX HCRF data (cf. Section 3.2) agree well with the albedo values measured in-situ. Moreover, the spatial pattern along each profile is highly similar except for a few single points, where the in-situ albedo values are larger. This disagreement can be explained by the presence of winter snow on 6th of August 2014 at these specific locations. The root-mean-square error (RMSE) is 0.076 , which is small considering the range of albedo values along the profiles $(0.1$ to 0.4$)$ and that the two datasets are from different years. Evaluating the albedo retrieval for snow-covered areas was difficult since no corresponding measurements are available for the time of APEX overflights. We instead compared in-situ point albedo measurements obtained on 3rd of July 2014 of the still fully snow-covered glacier to the snow albedo values derived from APEX HCRF data on 31th of August 2013. The comparability might be difficult since the measurements are not co-located and because of snow ageing effects. Nevertheless, the mean albedo for snow-covered areas derived from the APEX HCRF $(0.57 \pm 0.12)$ agrees well with the in-situ measured average snow albedo of 0.49 .

Uncertainties related to the measurement setup, i.e. size of the albedometer footprint compared to the APEX pixel size, are estimated by calculating standard deviations for $3 \times 3$ pixels surrounding the 27 in-situ measured points. The average standard deviation of 0.02 indicates that these uncertainties are negligible.

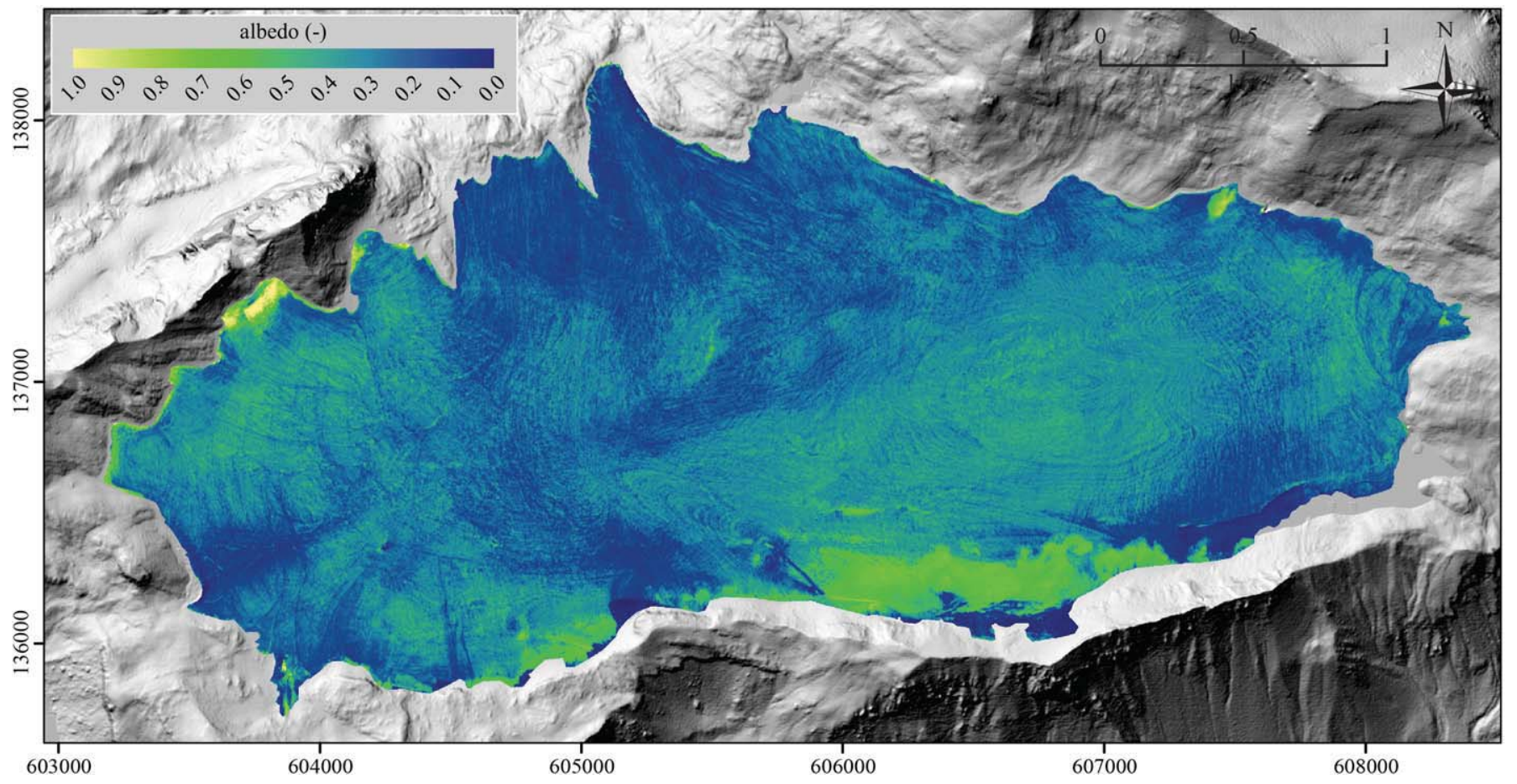

Fig. 6. Glacier surface albedo derived from APEX HCRF data. 


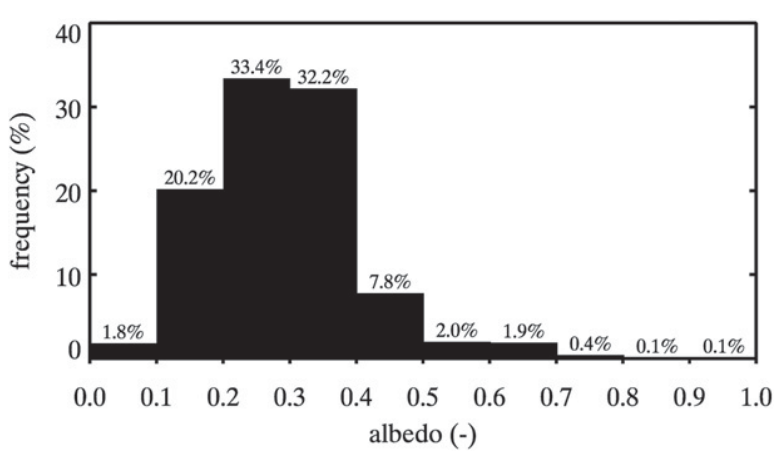

Fig. 7. Distribution of glacier surface albedo values.

\subsection{Distributed mass balance modelling}

State-of-the-art glacier mass balance models often simplify the representation of surface albedo due to a lack of input data. Spatially, albedo values are typically assumed as constant for the calculation of glacier surface mass balances (Gabbi, Carenzo, Pellicciotti, Bauder, \& Funk, 2014; Machguth et al., 2006; Nemec, Huybrechts, Rybak, \& Oerlemans, 2009; Pellicciotti et al., 2005). However, albedo is known to be a crucial parameter for glacier ablation (e.g. Jonsell, Hock, \& Holmgren, 2003; Klok \& Oerlemans, 2004). We therefore tested the impact of using spatially distributed albedo maps (Fig. 6) compared to a constant albedo value for predicting spatial variations in bare-ice melting. We applied the mass balance model described in Section 3.3 and calculated the surface mass balance using the spatially distributed ice albedo map in a first model run. It must be noted that the model is tuned to match the point measurements of accumulation and ablation (Fig. 1). For the second model run, a constant albedo value of 0.34 (following Oerlemans \& Knap, 1998) was used for glacier ice while all other parameters were kept constant. Differences between calculated mass balances thus directly indicate the local relevance of knowing ice albedo distribution for calculations of glacier melt rates. Fig. 9a and b illustrates the results of both model runs.

In general, overall glacier mass balances were found to be similar for both model runs, but slightly stronger melt $(+0.12 \mathrm{~m}$ w.e.) occurred while using the spatially distributed albedo map. We further tested the sensitivity of the mass balance of Glacier de la Plaine Morte with respect to albedo by using constant ice albedo values of 0.20 ("debrisrich ice" following Cuffey \& Paterson, 2010) and 0.29 (mean albedo value calculated based on APEX HCRF data cf. Section 4.3). This experiment revealed that lowering the constant ice albedo value by 0.05 and 0.14 increases the overall glacier mass loss by $10 \%$ and $27 \%$ for the year 2013, respectively. A difference map (Fig. 9c) indicates that there are large areas with no significant changes in ablation compared to the model run relying on a fixed albedo. However, large negative differences in calculated mass balance occur for other parts of the glacier, such as two areas in the western section of the glacier and the glacier tongue. In both areas, the ice surface is strongly contaminated with light-absorbing impurities (cf. Fig. 4) and/or covered by a thin water film. Another area with negative differences of modelled albedo is located in the south-east of the glacier, where a supraglacial lake deposits fine sediment every spring (cf. Fig. 1). Slightly positive differences occur in areas of the glacier where the spatially distributed albedo map shows greater albedo values than the fixed ice albedo (cf. Section 3.3 and Fig. 6).

The influence of spatially distributed albedo maps on calculated mean mass balance is also clearly visible for the two ablation stake clusters (Figs. 10 and cf. Section 2.6). We observed a considerable difference in measured ice melt between the two plots of about $0.15 \mathrm{~m}$ w.e. over the time period of 48 days, but the mass balance model relying on a fixed albedo (model run 2) only shows minor differences for the two sites. In contrast, model run 1 employing the albedo map allowed qualitatively reproducing the considerable ablation difference, emphasizing the importance of spatial ice surface albedo variations and their impact on glacier mass balance.

\section{Discussion}

\subsection{Mapping of glacier surface materials}

We found the SAM algorithm capable to distinguish different materials present on a glacier surface, which is consistent with studies in other research fields (e.g. Bell et al., 2010; Petropoulos, Vadrevu, Xanthopoulos, Karantounias, \& Scholze, 2010). The high spatial and spectral resolution of the APEX sensor enables a clear distinction between surface materials that have subtle spectral contrasts, e.g. ice and bright ice. However, a successful application of the SAM algorithm crucially depends on the choice of endmembers and requires expert knowledge on the local situation. Furthermore, the conversion of SAM spectral angles to abundance values relies on a proper understanding of actual surface compositions obtainable from field observations. The acquisition of field data is a laborious task and can only be reasonably realized if the site is well accessible.

The SAM algorithm is parameterized with so-called endmembers. These reference spectra can be either derived from the image itself or measured in-situ. Image endmembers have the disadvantage of not being pure but they are directly comparable to other image pixels since acquired and processed under the same conditions. In contrast, in-situ endmember spectra fulfil more the requirement to be spectrally pure but might not be representative for various reasons: The glacier surface is characterized by a great heterogeneity of various materials, which is hard to capture with direct measurements. Scaling issues
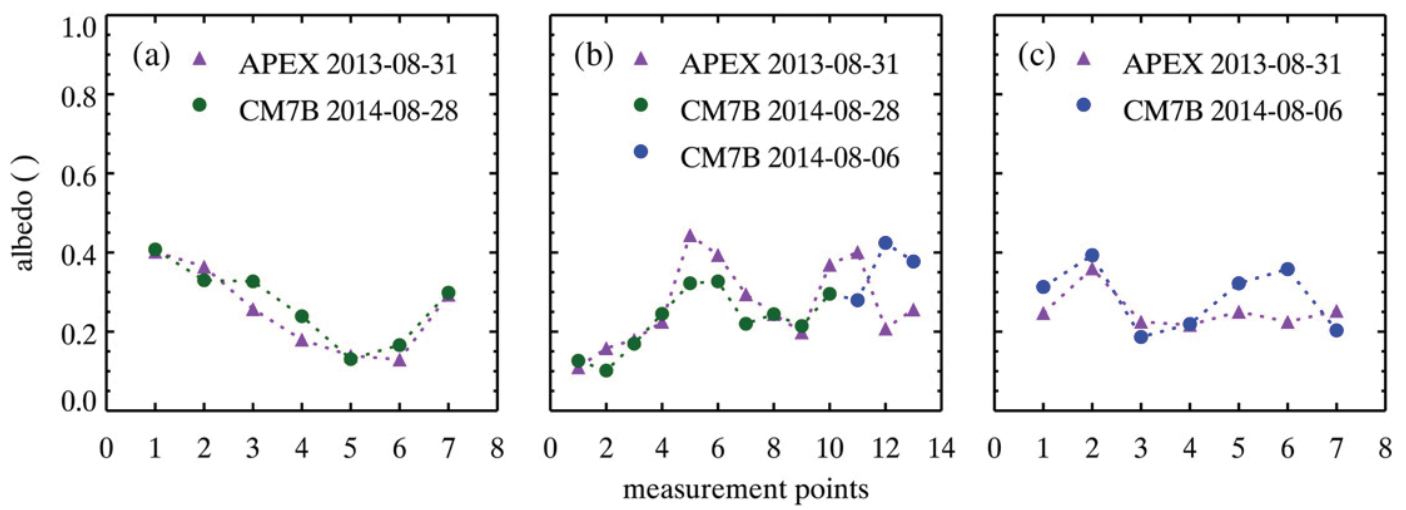

Fig. 8. Comparison of APEX derived albedo (purple triangles) and in-situ albedo measurements (green \& blue dots) taken with a Kipp \& Zonen CM7B, along three different profiles including 27 individual points. See Fig. 1 for location of the profiles. 

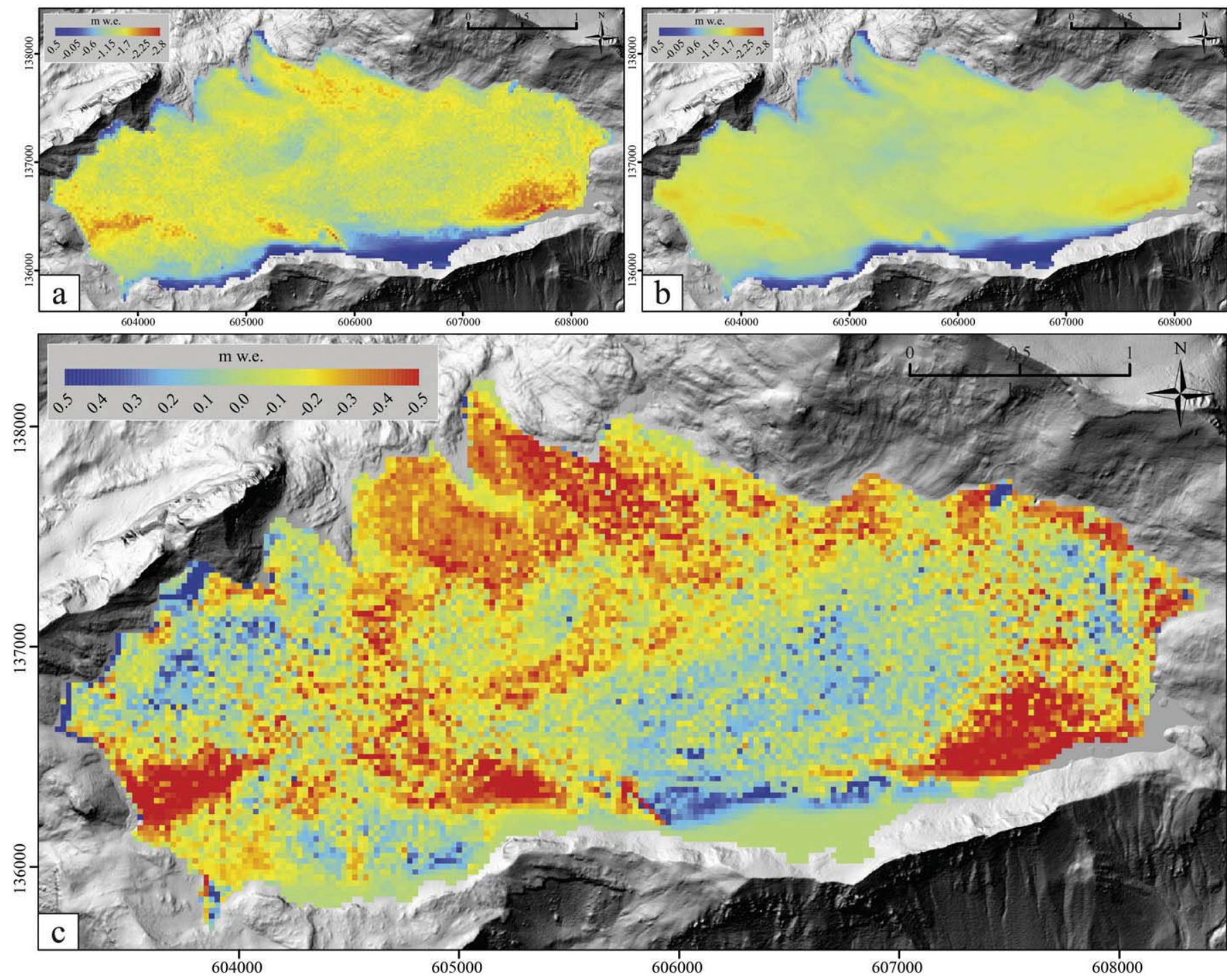

Fig. 9. Modelled surface mass balance: (a) model run 1 with spatially distributed albedo values for ice (cf. Fig. 6) and (b) model run 2 with constant albedo value for ice. (c) Difference between the two individual model runs, emphasizing regions where glacier surface albedo has a large influence on calculated mass balance.

between field and airborne data or small temporal differences in data acquisition likely cause additional uncertainties when combining image and field spectra. We hence decided to work with image endmembers in this study. Nevertheless, our in-situ measured spectral library provided important information during the data analysis and facilitated distinguishing the predominant materials and served as a valuable data set to evaluate the reliability of selected image endmember.

Concerning the definition of predominant materials present on glacier surfaces, one has to consider the discrepancy of scale and purity between materials resolvable from airborne imaging spectrometer data, from in-situ observations and materials exiting in reality. For glacier surfaces the presence of water is highly important, albeit extremely complex. It is therefore indispensable to clearly define endmembers to account for the fuzzy transitions of materials such as water, which can be an endmember itself but is also part of other endmembers, e.g. in snow or wet debris. Furthermore, it should be noted that the SAM-based abundance maps and surface classifications are approximations and might also represent material mixtures found on the glacier surface. In the context of our study it would be beneficial to develop approaches that are able to deal with a continuous degree of dirtiness instead of discrete surface classification. Such approaches would also allow improving the retrieval of spectral albedo values by combining and weighting the anisotropy effects estimated for pure classes at a sub-pixel base.

\subsection{Estimation of glacier surface albedo}

Broadband albedo, i.e. the albedo comprising the entire solar spectrum, is needed for mass balance calculations or other glaciological applications (Knap et al., 1999). This is nearly achieved in our study due to the large spectral range covered by APEX. We thus consider the derived spectral albedo map as representative for broadband albedo.

The actual albedo values computed from APEX HCRF data are in good agreement with other mean albedo values of glacier ice as reported in literature. Gabbi et al. (2014), for example, measured a mean ice albedo of $0.24 \pm 0.06$ for Rhonegletscher, Switzerland, in 2011, Oerlemans and Knap (1998) found an albedo of 0.35 for August 1996 on Morteratschgletscher, Switzerland, and Takeuchi (2002b) determined a mean surface albedo of 0.32 for the ablation area of Gulkana Glacier, Alaska, in 2000. Paul et al. (2005) derived minimum ice albedo values of between 0.1 and $0.2 \pm 0.05$ in the ablation areas of five Swiss glaciers, including Glacier de la Plaine Morte. The mean albedo of $0.29 \pm 0.12 \mathrm{com}-$ puted in the present assessment agrees well with the above studies but is significantly higher than the value found by Paul et al. (2005) for the same glacier. This difference can be attributed to the fact that Paul and others used Landsat Thematic Mapper images from 2003, while in 2003 the glacier was characterized by extreme glacier melt and the presence of melt water on the bare-ice surface. Further, applied methodologies differed, 


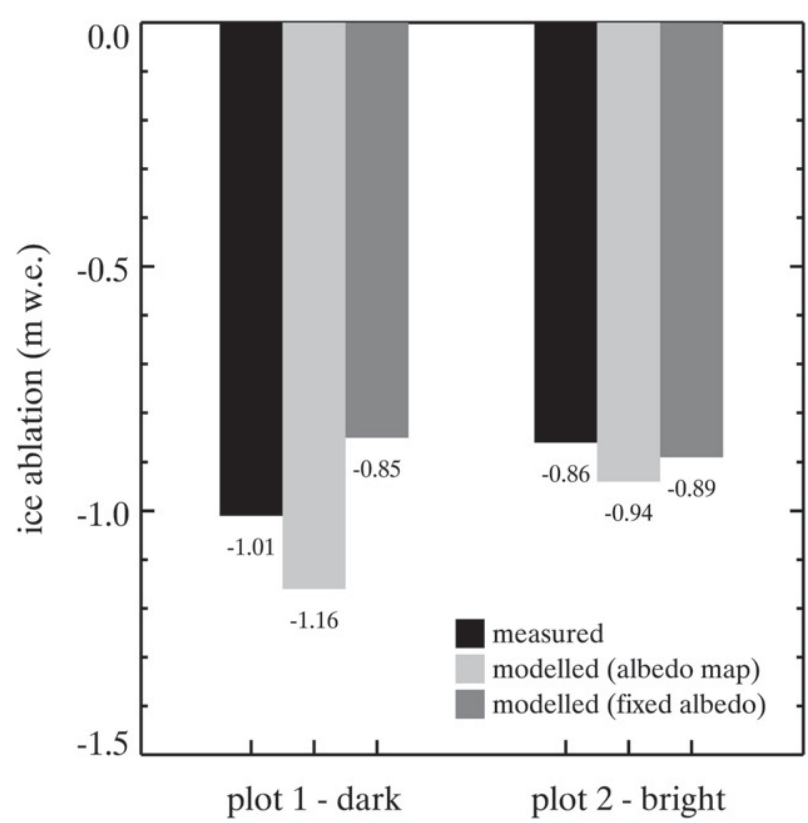

Fig. 10. Comparison of mean in-situ measured ice melt and modelling results of two different model runs (cf. Section 4.4) at the two ablation stake clusters (Fig. 1) between 16th August and 2nd October 2013.

e.g. consideration of BRDF effects, usage of satellite versus airborne versus in-situ data, also contributing to observed difference between our albedo values and the one reported in Paul et al. (2005).

From APEX measurements one can obtain HCRF values while the retrieval of albedo requires BHR values. The conversion form HCRF in BRF values relies on an exact characterization of the reflectance anisotropy of individual materials and their mixtures present on the glacier surface. However, measuring reflectance anisotropy effects is difficult both logistically and due to their change over time. In this study, we used directional in-situ data to make the link between HCRF and BHR values (cf. Sections 2.3 and 3.2) and our results indicate that this strategy is reasonable to obtain first results. However, the representativeness of used directional data is limited since only a few predominant surface types could be measured. Moreover, this approach requires field visits and expert knowledge on the local occurrence of materials on the glacier surface and is hence rather expensive. Multi-angular data at a regular temporal base, e.g. satellite-based imaging spectroscopy data from e.g. PROBA-1 on-board CHRIS would therefore be an optimal additional dataset.

A main advantage of our method is the ability to deal with discretely classified anisotropies for each pixel individually. Likely, improvements may be achieved when using a continual changing anisotropy (from forward to backward scattering), taking into account material dependent scattering abundances within pixels. In combination with assessing the impact of scattering properties of surface materials on glacier mass balance modelling, this would make an interesting experiment requiring a more sophisticated cause-effect analysis than possible with the present data.

\subsection{Impact of albedo on glacier mass balance modelling}

The availability of a distributed spectral albedo map allows evaluating the impact of spatial albedo variability on the calculation of glacier mass balance distribution. Comparing the modelled and observed mass balance at the four measurement sites (Fig. 1) reveals an RMSE of $0.13 \mathrm{~m}$ w.e.. In contrast, using a constant ice albedo value of 0.34 , 0.20 and 0.29 resulted in an RMSE of $0.25,0.21$ and $0.18 \mathrm{~m}$ w.e., respectively. This indicates that the ability of the model to reproduce the observed melt pattern is maximal if the pixel-based albedo is used and decreases with increasing deviations of the prescribed albedo value from the measured average. Furthermore, Fig. 9c shows regions with under- or overestimated mass balances, demonstrating a larger spatial variability of the mass balance usually not reproduced by models (cf. Fig. 9b). The improved performance of mass balance models using spatially distributed albedo maps is particularly important for very contrasting surfaces such as in the area of the two ablation stake clusters (cf. Fig. 10).

Modelled annual mass balances according to the two model runs only differ by $0.12 \mathrm{~m}$ w.e. (10\%), indicating that the literature-based fixed albedo value of 0.34 is a fairly well representation for the variety of albedo values present on the glacier surface. However, similarly to Paul et al. (2005), we could demonstrate that glacier surface albedo mostly impacts on the small-scale distribution of glacier mass balance. Hence, it is suggested to incorporate spatial pattern of glacier surface albedo in glacier mass balance models, especially if glaciers with complex and/or diverse surface characteristics are investigated.

\section{Conclusions}

We demonstrated the applicability and potential of imaging spectroscopy in the field of glaciology. Based on a combined use of in-situ and airborne imaging spectroscopy data, we retrieved a glacier surface inventory comprising quantitative and spatially distributed abundance information for six predominant materials present on Glacier de la Plaine Morte. The high information content of used APEX spectroscopy data was essential to differentiate the various surface materials, in particular the different material sub-types that are characterized by only subtle spectral contrasts. The surface inventory was an inevitable input to derive a spectral albedo map. Observed small-scale spatial variations in spectral albedo demonstrate the heterogeneity of glacier surfaces and indicate the need for more detailed analysis and suitable observational approaches such as imaging spectroscopy.

We found a mean albedo of $0.29 \pm 0.12$ for the entire glacier, but some areas showed considerably lower albedo values, highlighting the large variability in glacier surface albedo patterns. The ingestion of the spatial explicit spectral albedo map into a state-of-the-art mass balance model revealed notable spatial variations in modelled mass balances that strongly depend on the local albedo. While the simplified assumption of a constant albedo resulted in a similar overall mass balance for Glacier de la Plaine Morte in 2013, the lack of detailed and spatially explicit surface albedo values hinders reproducing the strong spatial variations in glacier ablation. Moreover, the performance of the mass balance model increased significantly using the spatially distributed albedo data set; model runs relying on a constant albedo revealed uncertainties of 38-93\%.

Our results contribute to the understanding of spatial variation in ice surface albedo and allow detecting the occurrence, composition, distribution, and impact of light-absorbing impurities on glacier surfaces using both in-situ and remote sensing data. Related to global atmospheric warming, observing and assessing the changes in ice surface albedo is crucial. Albedo is one of the most important factors in the energy balance of glaciers and the ice-albedo feedback might significantly accelerate glacier retreat worldwide. Therefore, more insights into the processes driving albedo variations in time and space are urgently needed in order to improve models for quantifying future ice melt at the local to global scale.

\section{Acknowledgement}

This study is funded within the SUK and ETH-board funded KIP-5 project Swiss Earth Observatory Network (SEON). We are grateful to the numerous people that contributed to the collection of in-situ data, in particular Ph. Schuppli and F. Denzinger. We thank the APEX team as well as R. de Jong and $\mathrm{H}$. Wulf for processing support. We further thank Remontées Mécaniques Crans Montana Aminona (CMA) for their logistic support and the Institute for Atmospheric and Climate Science, ETH (IACETH) for the loan of the CM7B albedometer during summer 2014. Weather data were obtained from MeteoSwiss and the orthoimage from the Federal Office of Topography swisstopo. Comments by two anonymous reviewers were helpful to finalize the paper. 
Appendix A
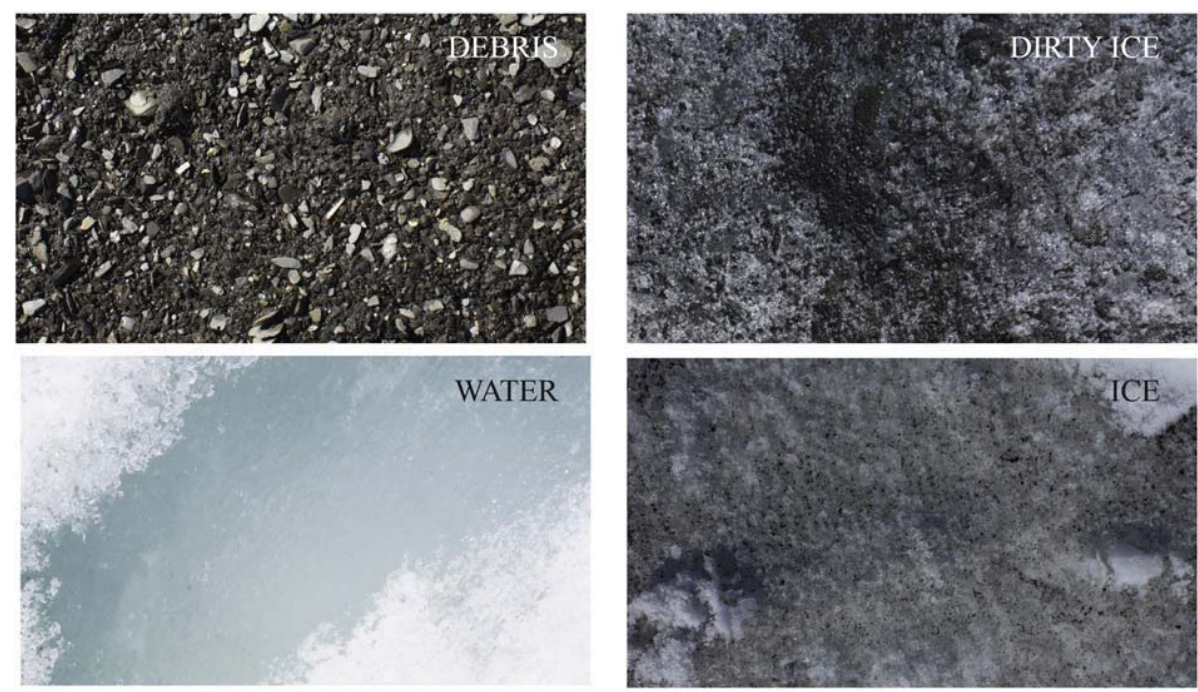

BRIGHT ICE

SNOW
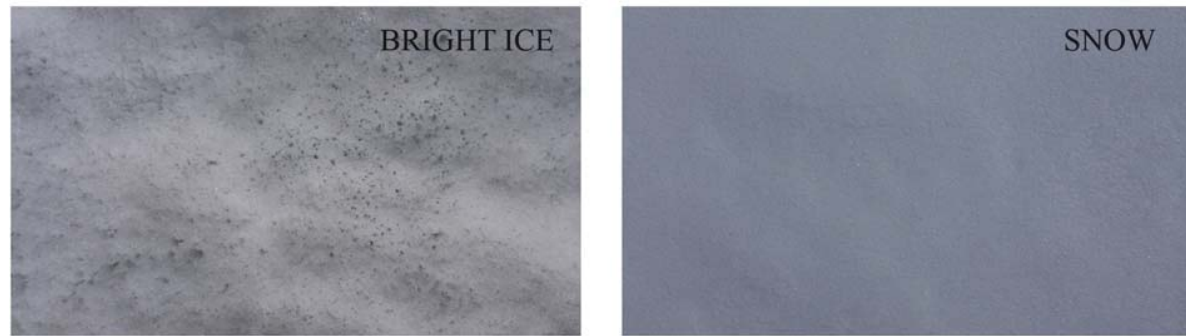

Fig. A1. Photos of the six predominant materials found on Glacier de la Plaine Morte and used as endmembers in all analysis.
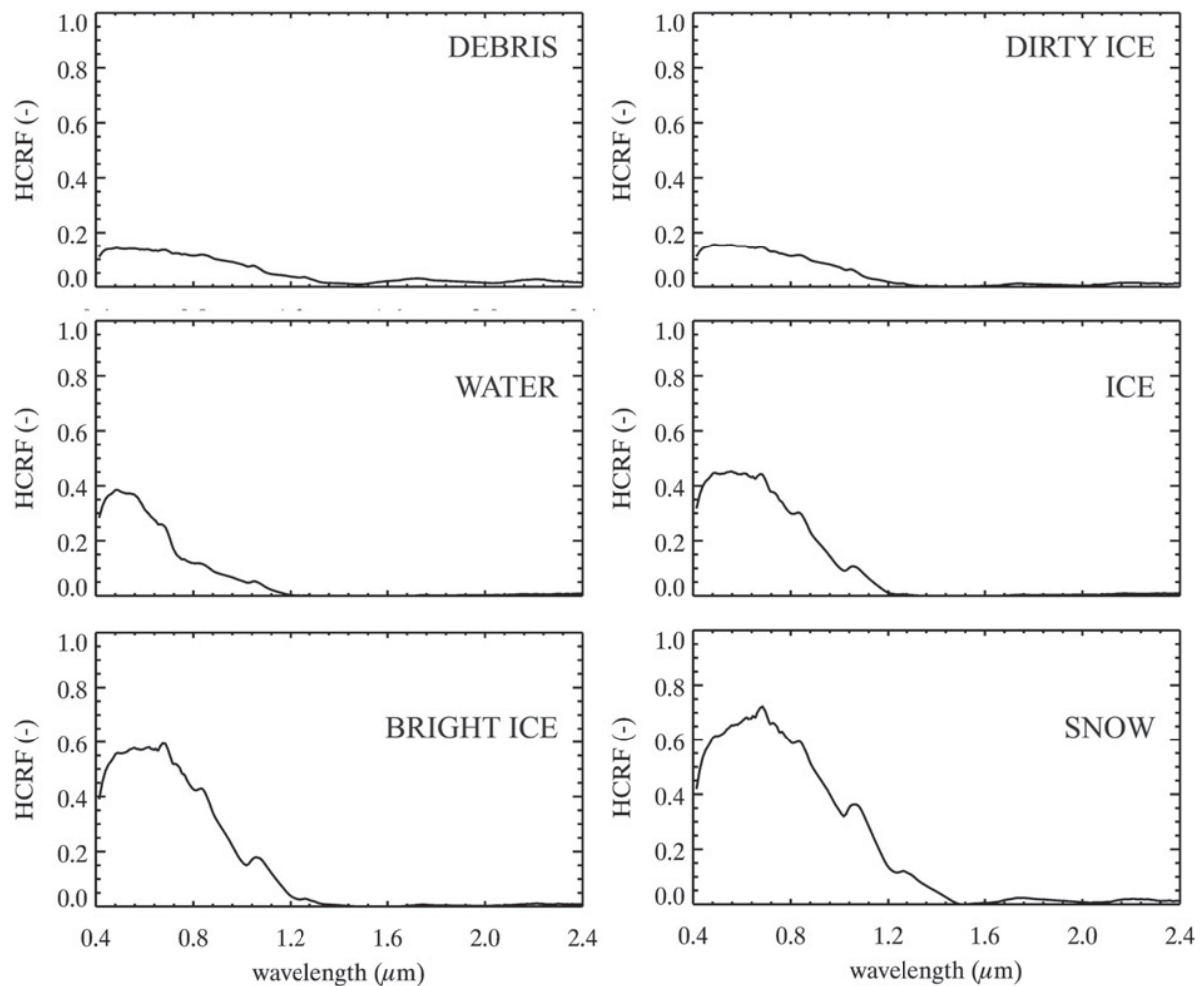

Fig. A2. Average spectra $(n=10)$ of the six predominant materials found on Glacier de la Plaine Morte extracted from the APEX scene. 

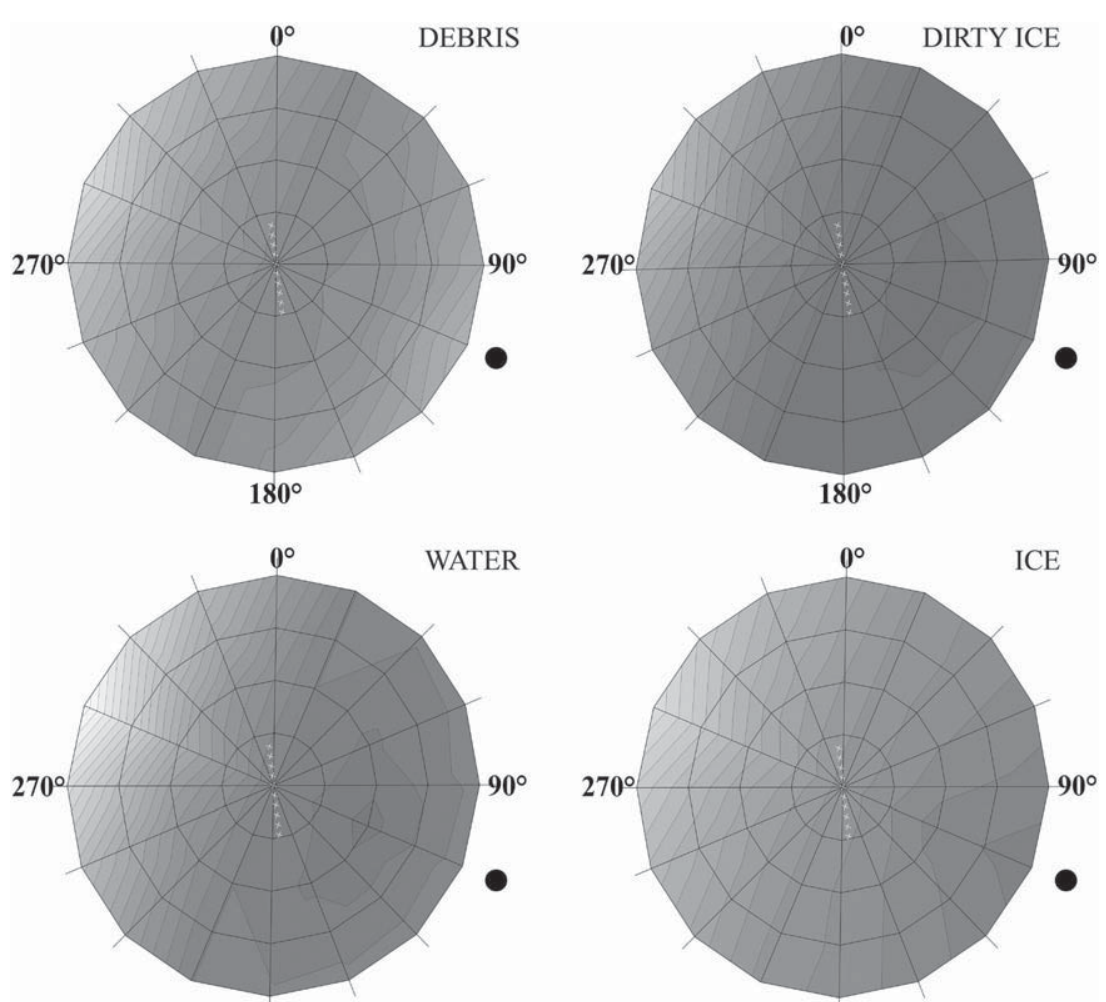

$180^{\circ}$

$180^{\circ}$

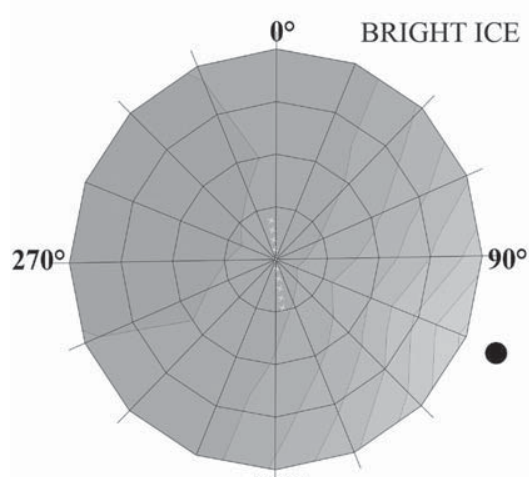

$180^{\circ}$

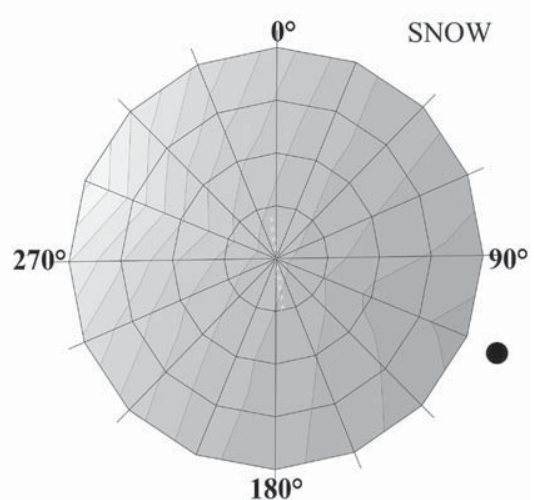

Fig. A3. 2D representation of the BRDF plots (polar plot) for the six predominant materials found on Glacier de la Plaine Morte. Reflectance values are indicated as grey values; contour lines are overlaid in black. The profile from left to right corresponds to the solar principle plain (W-E), the profile from bottom to top the perpendicular profile (S-N). The grey circles represent different view zenith angles in $15^{\circ}$ steps from $0-60^{\circ}$. The white crosses mark the position of APEX observations in the polar plots. The dark dot indicates the position of the sun. 

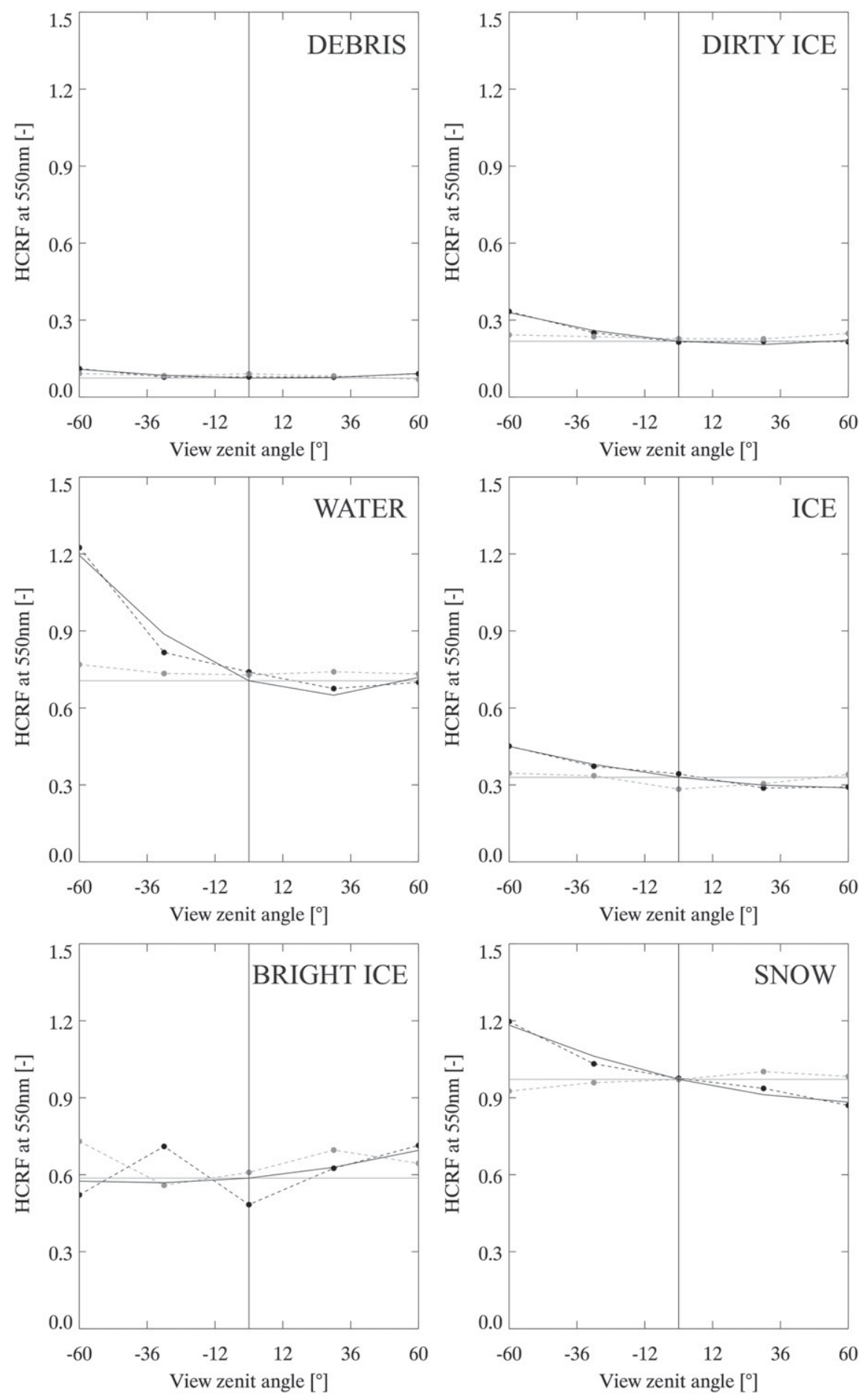

Fig. A4. In-situ measured ASD reflectance as function of varying view zenith angles for the six predominant materials found on Glacier de la Plaine Morte. Black lines: measurements in the solar principle plain; grey lines: measurements perpendicular to solar principle plain; Dashed lines: measurements; bold lines: interpolated and corrected measurements; $-60^{\circ}$ in the solar principle plain means that the sun was in front of the sensor; $60^{\circ}$ means that the sun was in the back of the sensor.

\section{References}

Alexander, P. M., Tedesco, M., Fettweis, X., van de Wal, R. S. W., Smeets, C. J. P. P., \& van den Broeke, M. R. (2014). Assessing spatio-temporal variability and trends in modelled and measured Greenland Ice Sheet albedo (2000-2013). The Cryosphere 8, 2293-2312. http://dx.doi.org/10.5194/tc-8-2293-2014.

Analytical Spectral Devices, I. (2014). FieldSpec 4. Retrieved from http://www.asdi.com/ products/fieldspec-spectroradiometers/fieldspec-4-standard-res

Aspinall, R. J. Marcus, A. W., \& Boardman, J. W. (2002). Considerations in collecting, processing, and analysing high spatial resolution hyperspectral data for environmental investigations. Journal of Geographical Systems, 4, 15-29.

Azzoni, R. S., Senese, A., Zerboni, A., Maugeri, M., Smiraglia, C., \& Diolaiuti, G. A. (2014). A novel integrated method to describe dust and fine supraglacial debris and their effects on ice albedo: the case study of Forni Glacier, Italian Alps. The Cryosphere Discussions, 8(3), 3171-3206. http://dx.doi.org/10.5194/tcd-8-3171-2014.

Bell, J. H., Breitler Bowen, B., \& Martini, B. A. (2010). Imaging spectroscopy of jarosite cement in the Jurassic Navajo Sandstone. Remote Sensing of Environment, 114(10), 2259-2270. http://dx.doi.org/10.1016/j.rse.2010.05.002.

Berk, A., Anderson, G. P., Acharya, P. K., Bernstein, L. S., Muratov, L., Lee, J., et al. (2005). MODTRAN 5: a reformulated atmospheric band model with auxiliary species and practical multiple scattering options: Update. Proceedings of SPIE. http://dx.doi.org/ $10.1117 / 12.606026$.

Casey, K. A. (2011). Supraglacial dust and debris characterization via in situ and optical remote sensing methods. University of Oslo.

Cescatti, A., Marcolla, B., Santhana Vannan, S. K., Pan, J. Y., Román, M. O., Yang, X., et al. (2012). Intercomparison of MODIS albedo retrievals and in situ measurements across 
the global FLUXNET network. Remote Sensing of Environment, 121, 323-334. http://dx. doi.org/10.1016/j.rse.2012.02.019.

Chandler, D. M., Alcock, J. D., Wadham, J. L., Mackie, S. L., \& Telling, J. (2014). Seasonal changes of ice surface characteristics and productivity in the ablation zone of the Greenland Ice Sheet. The Cryosphere, 9, 487-504. http://dx.doi.org/10.5194/tcd-81337-2014.

Cohen, J. (1960). A coefficient of agreement for nominal scales. Educational and Psychological Measurement, XX(1), 37-46.

Cuffey, K. M., \& Paterson, W. S. B. (2010). The physics of glaciers. Elsevier Science.

Dozier, J., Green, R. O., Nolin, A. W., \& Painter, T. H. (2009). Interpretation of snow properties from imaging spectrometry. Remote Sensing of Environment, 113, S25-S37. http://dx.doi.org/10.1016/j.rse.2007.07.029.

Dumont, M., Brun, E., Picard, G., Michou, M., Libois, Q., Petit, J. -R., et al. (2014). Contribution of light-absorbing impurities in snow to Greenland's darkening since 2009. Nature Geoscience, 7, 509-512. http://dx.doi.org/10.1038/ngeo2180.

Dumont, M., Gardelle, J., Sirguey, P., Guillot, A., Six, D., Rabatel, A., et al. (2012). Linking glacier annual mass balance and glacier albedo retrieved from MODIS data. The Cryosphere, 6, 1527-1539. http://dx.doi.org/10.5194/tc-6-1527-2012.

Exelis Visual Information Solutions, I (2013). ENVI classic tutorial: Selected hyperspectral mapping methods.

Finger, D., Hugentobler, A., Huss, M., Voinesco, A., Wernli, H., Fischer, D., et al. (2013). Identification of glacial melt water runoff in a karstic environment and its implication for present and future water availability. Hydrology and Earth System Sciences Discussions, 10, 2743-2788. http://dx.doi.org/10.5194/hessd-10-2743-2013.

Fitzpatrick, A. A. W., Hubbard, A. L., Box, J. E., Quincey, D. J., Van As, D., Mikkelsen, A. P. B., et al. (2014). A decade (2002-2012) of supraglacial lake volume estimates across Russell Glacier, West Greenland. The Cryosphere, 8(1), 107-121. http://dx.doi.org/ $10.5194 /$ tc-8-107-2014.

Flanner, M. G., Zender, C. S., Randerson, J. T., \& Rasch, P. J. (2007). Present-day climate forcing and response from black carbon in snow. Journal of Geophysical Research, [Atmospheres], 112(11), 1-17. http://dx.doi.org/10.1029/2006JD008003.

Foody, G. M. (2002). Status of land cover classification accuracy assessment. Remote Sensing of Environment, 80, 185-201. http://dx.doi.org/10.1016/S0034-4257(01)00295-4.

Gabbi, J., Carenzo, M., Pellicciotti, F., Bauder, A., \& Funk, M. (2014). A comparison of empirical and physically based glacier surface melt models for long-term simulations of glacier response. Journal of Glaciology, 60(224), 1140-1154. http://dx.doi.org/10. 3189/2014JoG14J011.

Hodson, A., Cameron, K., Bøggild, C., Irvine-Fynn, T., Langford, H., Pearce, D., et al. (2010). The structure, biological activity and biogeochemistry of cryoconite aggregates upon an Arctic valley glacier: Longyearbreen, Svalbard. Journal of Glaciology, 56(196), 349-362. http://dx.doi.org/10.3189/002214310791968403.

Hueni, A., Lenhard, K., Baumgartner, A., \& Schaepman, M. E. (2013). Airborne prism experiment calibration information system. IEEE Transactions on Geoscience and Remote Sensing, 1-12.

Huss, M., Bauder, A., \& Funk, M. (2009). Homogenization of long-term mass-balance time series. Annals of Glaciology, 50(50), 198-206. http://dx.doi.org/10.3189/ 172756409787769627.

Huss, M., Voinesco, A., \& Hoelzle, M. (2013). Implications of climate change on Glacier de la Plaine Morte, Switzerland. Geographica Helvetica, 68(4), 227-237. http://dx.doi. org/10.5194/gh-68-227-2013.

Huss, M., Zemp, M., Joerg, P. C., \& Salzmann, N. (2014). High uncertainty in 21st century runoff projections from glacierized basins. Journal of Hydrology, 510, 35-48. http://dx.doi.org/10.1016/j.jhydrol.2013.12.017.

Irvine-Fynn, T. D. L., Bridge, J. W., \& Hodson, A. J. (2011). In situ quantification of supraglacial cryoconite morphodynamics using time-lapse imaging: An example from Svalbard. Journal of Glaciology, 57(204), 651-657. http://dx.doi.org/10.3189/ 002214311797409695.

Jehle, M., Hueni, A., Damm, A., D'Odorico, P., Weyermann, J., Kneubühler, M., et al. (2010). APEX - current status, performance and validation concept. IEEE Sensors, 533-537.

Joerg, P. C., Weyermann, J., Morsdorf, F., Zemp, M., \& Schaepman, M. E. (2015). Computation of a distributed glacier surface albedo proxy using airborne laser scanning intensity data and in-situ spectro-radiometric measurements. Remote Sensing of Environment 160, 31-42. http://dx.doi.org/10.1016/j.rse.2014.12.017.

Jonsell, U., Hock, R., \& Holmgren, B. (2003). Spatial and temporal variations in albedo on Storglaciären, Sweden. Journal of Glaciology, 49(164), 59-68. http://dx.doi.org/10 3189/172756503781830980.

Klein, A. G., \& Isacks, B. L. (1999). Spectral mixture analysis of Landsat thematic mapper images applied to the detection of the transient snowline on tropical Andean glaciers. Global and Planetary Change, 22, 139-154. http://dx.doi.org/10.1016/S09218181(99)00032-6.

Klok, E. J. \& Oerlemans, J. (2004). Modelled climate sensitivity of the mass balance of Morteratschgletscher and its dependence on albedo parameterization. International Journal of Climatology, 24(2), 231-245. http://dx.doi.org/10.1002/joc.994.

Knap, W. H., Reijmer, C. H., \& Oerlemans, J. (1999). Narrowband to broadband conversion of Landsat TM glacier albedos. International Journal of Remote Sensing, 20(10), 2091-2110. http://dx.doi.org/10.1080/014311699212362.

Kruse, F. A., Lefkoff, A. B., Boardman, J. W., Heidebrecht, K. B., Shapiro, A. T., Barloon, P. J., et al. (1993). The spectral image processing system (SIPS) - Interactive visualization and analysis of imaging spectrometer data. Remote Sensing of Environment, 44, $145-163$.

Langford, H., Hodson, A., Banwart, S., \& Bøggild, C. (2010). The microstructure and biogeochemistry of Arctic cryoconite granules. Annals of Glaciology, 51(56), 87-94. http://dx. doi.org/10.3189/172756411795932083.

Legleiter, C. J., Tedesco, M., Smith, L. C., Behar, A. E., \& Overstreet, B. T. (2014). Mapping the bathymetry of supraglacial lakes and streams on the Greenland ice sheet using field measurements and high-resolution satellite images. The Cryosphere Cryosphere, 8 , 215-228. http://dx.doi.org/10.5194/tc-8-215-2014.

Machguth, H., Paul, F., Hoelzle, M., \& Haeberli, W. (2006). Distributed glacier mass-balance modelling as an important component of modern multi-level glacier monitoring. Annals of Glaciology, 43(1), 335-343. http://dx.doi.org/10.3189/172756406781812285.

Monserud, R. A., \& Leemans, R. (1992). Comparing global vegetation maps with the Kappa statistic. Ecological Modelling, 62, 275-293.

Nemec, J., Huybrechts, P., Rybak, O., \& Oerlemans, J. (2009). Reconstruction of the annual balance of Vadret da Morteratsch, Switzerland, since 1865, (2002), 126-134.

Nolin, A. W., \& Dozier, J. (2000). A hyperspectral method for remotely sensing the grain size of snow, 216(March). (pp. 207-216), 207-216.

Nolin, A. W., \& Payne, M. C. (2007). Classification of glacier zones in western Greenland using albedo and surface roughness from the Multi-angle Imaging SpectroRadiometer (MISR). Remote Sensing of Environment, 107(1-2), 264-275. http://dx.doi.org/10. 1016/j.rse.2006.11.004.

Oerlemans, J. (2001). Glaciers and climate change. CRC Press.

Oerlemans, J., Giesen, R. H., \& Van Den Broeke, M. R. (2009). Retreating alpine glaciers: increased melt rates due to accumulation of dust (Vadret da Morteratsch, Switzerland). Journal of Glaciology, 55(192), 729-736. http://dx.doi.org/10.3189/ 002214309789470969

Oerlemans, J., \& Knap, W. H. (1998). A 1 year record of global radiation and albedo in the ablation zone of Morteratschgletscher, Switzerland. Journal of Glaciology, 44(147), 231-238.

Painter, T. H., Bryant, A. C., \& McKenzie Skiles, S. (2012). Radiative forcing by light absorbing impurities in snow from MODIS surface reflectance data. Geophysical Research Letters, 39(17), 1-7. http://dx.doi.org/10.1029/2012GL052457.

Painter, T. H., Rittger, K., McKenzie, C., Slaughter, P., Davis, R. E., \& Dozier, J. (2009). Retrieval of subpixel snow covered area, grain size, and albedo from MODIS. Remote Sensing of Environment, 113, 868-879. http://dx.doi.org/10.1016/j.rse.2009. 01.001.

Painter, T. H., Seidel, F. C., Bryant, A. C., McKenzie Skiles, S., \& Rittger, K. (2013). Imaging spectroscopy of albedo and radiative forcing by light-absorbing impurities in mountain snow. Journal of Geophysical Research, [Atmospheres], 118, 9511-9523. http://dx.doi.org/10.1002/jgrd.50520.

Paul, F., Machguth, H., \& Kääb, A. (2005). On the impact of glacier albedo under conditions of extreme glacier melt: the summer of 2003 in the Alps. EARSeL eProceedings, 4(2), $139-149$.

Pedersen, C. A., Berntsen, T. K., Gerland, S., \& Warren, S. G. (2010). Black carbon in snow Sampling, albedo effects and climate impact. Kortrapport/Brief Report Series Nr 17. Norsk Polar Institutt, Tromsø.

Pellicciotti, F., Brock, B., Strasser, U., Burlando, P., Funk, M., \& Corripio, J. (2005). An enhanced temperature-index glacier melt model including the shortwave radiation balance: Development and testing for Haut Glacier d'Arolla, Switzerland. Journal of Glaciology, 51(175), 573-587.

Petropoulos, G. P., Vadrevu, K. P., Xanthopoulos, G., Karantounias, G., \& Scholze, M. (2010). A comparison of spectral angle mapper and artificial neural network classifiers combined with Landsat TM imagery analysis for obtaining burnt area mapping. Sensors, 10, 1967-1985. http://dx.doi.org/10.3390/s100301967.

Pope, A., \& Rees, G. (2014). Using in situ spectra to explore Landsat classification of glacier surfaces. International Journal of Applied Earth Observation and Geoinformation, 27, 42-52. http://dx.doi.org/10.1016/j.jag.2013.08.007.

Richter, R., \& Schläpfer, D. (2002). Geo-atmospheric processing of airborne imaging spectrometry data. Part 2: Atmospheric/topographic correction. International Journal of Remote Sensing, 23(13), 2631-2649. http://dx.doi.org/10.1080/01431160110115834.

Rogge, D., Bachmann, M., Rivard, B., \& Feng, J. (2012). Hyperspectral flight-line leveling and scattering correction for image mosaics. IEEE IGARSS 2012 (pp. 4094-4097).

Schaepman, M. E. Jehle, M., Hueni, A., D'Odorico, P., Damm, A, Weyermann, J., et al. (2015). Advanced radiometry measurements and Earth science applications with the Airborne Prism Experiment (APEX). Remote Sensing of Environment, 158, 207-219. http://dx.doi.org/10.1016/j.rse.2014.11.014.

Schaepman-Strub, G. Schaepman, M. E., Painter, T. H., Dangel, S. \& Martonchik, J. V. (2006). Reflectance quantities in optical remote sensing - Definitions and case studies. Remote Sensing of Environment, 103(1), 27-42. http://dx.doi.org/10.1016/j. rse.2006.03.002.

Schläpfer, D., \& Richter, R. (2002). Geo-atmospheric processing of airborne imaging spectrometry data. Part 1: Parametric orthorectification. International Journal of Remote Sensing, 23(13), 2609-2630. http://dx.doi.org/10.1080/01431160110115825.

Swisstopo (2005). DHM25 - Das digitale Höhenmodell der Schweiz. Wabern.

Takeuchi, N. (2001). Structure, formation, and darkening process of albedo-reducing material (cryoconite) on a himalayan glacier: A granular algal mat growing on the glacier. Arctic, Antarctic, and Alpine Research and Alpine Research, 33(2), 115-122.

Takeuchi, N. (2002a). Optical characteristics of cryoconite (surface dust) on glaciers: The relationship between light absorbency and the property of organic matter contained in the cryoconite. Annals of Glaciology, 34, 409-414.

Takeuchi, N. (2002b). Surface albedo and characteristics of cryoconite (biogenic surface dust) on an Alaska glacier, Gulkana Glacier in the Alaska Range. Bulletin of Glaciological Research, 19, 63-70.

Wharton, R. A., McKay, C. P., Simmons, G. M., \& Parker, B. C. (1985). Cryoconite holes on glaciers. Bioscience, 35(8), 499-503 (Retrieved from http://www.ncbi.nlm.nih.gov/ pubmed/11539025).

Xu, B., Cao, J., Hansen, J., Yao, T., Joswia, D. R., Wang, N., et al. (2009). Black soot and the survival of Tibetan glaciers. Proceedings of the National Academy of Sciences of the United States of America, 106(52), 22114-22118. http://dx.doi.org/10.1073/pnas. 0910444106. 